\title{
RECOVERY OF BYPASSED OIL IN THE DUNDEE FORMATION USING HORIZONTAL DRAINS
}

Cooperative Agreement No.: DE-FC22-94BC14983

Contractor Name and Address: Michigan Technological University, 1400 Townsend

Drive, Houghton, MI 49931-1295

Date of Report: 30 April 1996

Award Date: 28 April 1994

Anticipated Completion Date: 27 April 1997

Government Award for Current Fiscal Year: $\$ 800,000$.

Principal Investigator: James R. Wood (906) 487-2894

Project Manager: Chandra Nautiyal, Bartlesville Project Office (918) 337-4418

Reporting Period: May 1, 1995 - April 30, 1996

\section{OBJECTIVE}

The principal objective of this project is to demonstrate the feasibility and economic success of producing oil from abandoned or nearly abandoned fields in the Dundee Formation of Central Michigan using horizontal driling technology. The project is a cooperative venture between Michigan Technological University (MTU), Western Michigan University (WMU), and Terra Energy (now Cronus Development Co.).

A site for a horizontal well was selected in Crystal Field, a nearly-abandoned Dundee oil field in Michigan. This field had produced over 8 million barrels of oil, mostly in the 1930's and 1940's. At the height of development, Crystal Field produced from 193 wells, but by 1995 , only seven producing wells remained, each producing less than $10 \mathrm{bbls} /$ day. A horizontal well was drilled as a field demonstration pilot, funded through this DOE project, and was immensely successful. Core and logs from the Dundee interval were recovered from a vertical borehole at the same surface location. The horizontal well was brought on production at a rate of $100 \mathrm{bbls} /$ day and is probably capable of producing at a higher rate. The addition of several horizontal wells, similar to the demonstration well, 
will likely add another 2 million bbls (or more) to the cumulative production of the field over the next few years. The presence of untapped oil in this Dundee field was dramatically demonstrated and the favorable economics were made clearly evident. If other abandoned Dundee fields are re-developed in a similar manner, the additional oil produced could exceed 80 million barrels. Horizontal drilling will likely revolutionize the development of old carbonate fields such as those in the Dundee of Michigan.

Additional project work comprises characterization of 30 other Dundee fields in Michigan to aid in determining appropriate candidates for development through horizontal drilling. Further quantification of reservoir parameters such as importance of fracturing, fracture density, and irregularity of the dolomitized surface at the top of the reservoir will help in designing the optimal strategy for horizontal drilling.

Technology transfer takes place continuously, through the Michigan Oil Field Research Consortium (MOFRC) and its Newsletter. Reviews in the popular press have helped reach additional audiences. The success of the demonstration well has been recognized by independent operators, who have requested copies of information published the Newsletter, and who have expressed interest in attending workshops which are being planned for this year. The creation of an "Atlas of Michigan Dundee Reservoirs" is planned as a no-cost addition to this project. The Atlas will greatly enhance the capability of small operators in the state to independently explore and develop this neglected resource.

\section{EXECUTIVE SUMMARY}

During the fall of 1995, the demonstration well for this project, the TOW No. 1-3 well in Crystal Field, Montcalm County, Michigan, was completed in the Dundee Formation and for the first three months of operation produced $50 \mathrm{bbl} /$ day oil with no water cut. Because surface facilities were inadequate to handle full production, the well was produced for 12 $\mathrm{hrs} /$ day and shut in for $12 \mathrm{hrs} /$ day. In January, 1996, new surface facilities were completed and production was raised to $100 \mathrm{bbl} /$ day. Daily production has varied from about 75 to 100 BOPD since that time. To date, the well has produced over $10,000 \mathrm{bbls}$. The water cut remains at $0 \%$ and pressure has been maintained at 1445 psi by an active water drive. If expectations are met, the well will pay out in less than 1 year and continue on production for at least 5 years. Cronus Development Co. is tentatively planning to drill three more horizontal wells in the Dundee in Crystal Field. Thus, the play concept we chose to test, that bypassed attic oil remained in the Dundee reservoir between wells that had been produced at excessively high flow rates and had coned water during primary production, appears to be correct, and the TOW No. 1-3 HD-1 well is now a scientific, and appears soon to become an economic, success.

The TOW No. 1-3 HD-1 well was spudded on September 20, 1995 and cored and logged through the Dundee. One and one half weeks later, $59.3 \mathrm{ft}$ of core was recovered from the top of the Dundee and the well was then drilled $150 \mathrm{ft}$ below the base of the core to TD at the top of the Detroit River anhydrite. The vertical well was then logged from TD 
at the base of the Dundee ( $3334 \mathrm{ft}$ ) to the base of casing ( $683 \mathrm{ft}$ ), which corresponds approximately to the base of the glacial till. Haliburton ran 3 consecutive log suites, which included: 1) a gamma ray and dual laterolog with microresistivity, 2) a lithodensity log (compensated formation density plus photoelectric factor), and 3) a compensated neutron log. The logs were then correlated with a high degree of confidence and combined. The top portion of the Dundee displayed good oil staining in the core. Therefore, the log suite has good coverage of both the oil leg and the water leg in the Dundee Formation. This was later confirmed by residual fluid saturation analyses of core samples.

As described above, the TOW No. 1-3 well was cored through the upper $60 \mathrm{ft}$ of the Dundee Formation and drilled to the base of the Dundee. During drilling through the Dundee, several lost-circulation events were experienced. After completion of the logging run, the well was cemented and plugged back to the top of the Traverse Lime and a 10 in. directional wellbore was drilled on the curve to convert the vertical well to a horizontal one. It took three days and 600 vertical feet to drill the curve and when the horizontal leg entered the Dundee, it was $400 \mathrm{ft}$ laterally distant from the original intercept of the vertical well with the top of the Dundee. The curve was then lined with $85 / 8$ in. casing and drilling of the 7 7/8 in. horizontal leg commenced. A Measurement While Drilling (MWD) gamma ray log was run to monitor orientation of the horizontal well bore.

A horizontal leg of $1800 \mathrm{ft}$ was originally planned, but $90 \mathrm{ft}$ into the horizontal leg, the well encountered a pocket of high porosity (probably vugs and fractures) and a major lostcirculation event ensued. The well blew out, but was immediately brought under control by blowout preventers. At the time that circulation was lost, the well was being drilled with a mud capable of holding 1500 psi. Because of the high reservoir porosity, permeability, and pressure and the propensity to lost circulation in the area penetrated by the horizontal wellbore, it was decided to suspend horizontal drilling and to complete the well in the Dundee.

Dolomite extends almost to the top of the Dundee, and the nonporous cap limestone, which is normally $10-15 \mathrm{ft}$ thick in much of Crystal Field, is only $2 \mathrm{ft}$ thick in the TOW No. 1-3 well. The upper $15 \mathrm{ft}$ of the Dundee is heavily fractured in core and contains centimeter-sized vugs. Most fractures are subvertical with highly variable azimuths, but some fractures are developed at lower angles. Most fractures and vugs are lined with white, sparry dolomite. The top of the Dundee in the demonstration well was encountered $8 \mathrm{ft}$ lower than projected. Together, these observations suggest that a top-down solution process (karst?) may have led to fracturing and collapse of the uppermost Dundee, which resulted in development of enhanced porosity.

Twenty nine feet of higher residual oil saturations at the top of the Dundee (3190-3219 ft) in the core indicate significant unrecovered oil. Beneath that, seven feet of lower residual oil saturations (3219-3226 ft) indicate either a transition zone or a swept zone where the oil-water contact moved up as a result of primary oil production. In the water leg below $3226 \mathrm{ft}$, residual oil saturations are $0.0 \%$. 
As part of this project, the Dundee reservoir is being characterized in 29 additional fields in central Michigan to encourage operators to consider horizontal drilling in other old Dundee fields. Well-log analysis and regional geological studies are being carried out by W. Harrison and his graduate students at WMU. Well data, including drillers' logs and wireline logs for the 8526 wells in our seven-county study area, which includes 4785 wells that penetrate the Dundee, were acquired from Maness Petroleum Co. and are now in our oil and gas well data set. Formation tops have been picked for all formations in all wells. Maps and cross sections have been completed for Crystal Field and for the 30 other Dundee oil fields in the study area. All these maps have been plotted on $81 / 2 \times 11$ pages and have been assembled by field into single "folio" sized poster sheets. These maps and cross sections are currently being compiled into notebooks for each field, along with field and reservoir data, field production histories and decline curves, type logs, and core data. These notebooks will be combined with an overview and summary evaluation volume to form an "Atlas of Michigan Dundee Reservoirs". To date, our evaluation of the data indicates that initial production $(\mathrm{IP})$ maps and production decline curves are the most useful tools for identifying prospective areas for horizontal drilling.

Microsoft Access is our relational database management platform. All of the log data are stored in Access in LAS format. All other data are stored in Toolbook, (a Multimedia archive and display program), and are accessible via pulldown menus and a Table of Contents with hot links. Instructions for retrieving logs from the Access database are included in the Toolbook multimedia archive. Users can search the database by query and retrieve the logs from the main database table by well or by log type. Logs are then placed in smaller temporary Access tables from which they can be exported to applications programs. When the project is completed, our Toolbook Multimedia Database will be written to CD ROM and made available to the public.

The GeoGraphix Exploration System software package was acquired in fall 1995 and installed on a PC in the Subsurface Laboratory at MTU. Since that time, MTU has acquired an academic license and three additional seats on GeoGraphix. Well-location data were loaded from the 51,359-well database that we acquired from Angstrom Precision. Formation-tops of all formations penetrated by all 51,359 wells and Dundee initial production (IP) values for all wells in several fields were input to GeoGraphix and selected maps and cross sections were constructed.

We plan to create an "Atlas of Michigan Dundee Reservoirs", using the maps and cross sections of our 30 project fields as a cornerstone of the publication. As envisioned, this Atlas will include a regional overview of Dundee stratigraphy and reservoir variability; development history of the trend, including comparisons between different fields; production history, including a discussion of engineering and completion techniques; and a table of important reservoir parameters for use in characterizing the Dundee reservoir in other old fields for which little data is available. The main body of the Atlas will consist of individual discussions of reservoir geology, engineering practices, and tables of reservoir parameters for each Dundee field. Discussion of the importance of fracturing, fracture density, and irregularity of the dolomitized surface will aid in the design of the optimal 
strategy for horizontal drilling. This Atlas will undoubtedly enhance the capability of small operators in the state to independently explore and develop this neglected resource. The Michigan Basin Geological Society has expressed interest in publishing the Atlas.

\section{SUMMARY OF TECHNICAL PROGRESS BY TASK}

\section{PROJECT MANAGEMENT}

\section{COORDINATION}

Several people joined the project this year. A. Wylie entered the Ph.D. program in Geology at MTU. He will be working under the direction of J. Huntoon on problems related to the Michigan Basin. Mr. Wylie has extensive experience in the oil industry and is expert in the use of the GeoGraphix Exploration System. C. Asiala was hired as a parttime database programmer, and $\mathrm{M}$. Sivek was hired as an undergraduate assistant to help in the programming. Two new students, W. Everham and M. Slis, joined the project and are correcting formatting problems and errors in the 51,359-well Angstrom database, which is currently being used in the GeoGraphix Exploration System. Postdoctoral Research Associate M. Luo, who has played an integral role in several other major research projects at MTU, began working on 3-D surface and volume visualizations in the statistical and visualization software package MatLab, aided by graduate student $B$. Wei.

Part of Terra Energy was sold in September, 1995. The new company which holds the rights to Crystal Field is called Cronus Development Co. All of the people at Terra who were involved in planning and drilling our project demonstration well are now with Cronus, so project continuity is assured.

Weekly staff meetings were established at MTU and are held every Tuesday and Thursday.

\section{BUDGET AND REPORTS}

M. Gruener and A. Hein are responsible for daily management of the budget and expenditures. A. Hein is responsible for preparation of quarterly financial reports and for distribution of all reports to DOE. J. Allan is responsible for quarterly and annual technical reports.

\section{RESERVOIR CHARACTERIZATION}

During the fall of 1995 , the demonstration well for this project, the TOW No. 1-3 well in Crystal Field, was completed in the Dundee Formation and for the first three months of operation produced $50 \mathrm{bbl} /$ day oil with no water cut. Because surface facilities were inadequate to handle full production, the well was produced for $12 \mathrm{hrs} /$ day and shut in for $12 \mathrm{hrs} /$ day. In January, 1996, new surface facilities were completed and production was 
raised to $100 \mathrm{bbl} /$ day. Daily production has varied from about 75 to $100 \mathrm{BOPD}$ since that time. To date, the well has produced over 10,000 bbls. The water cut remains at $0 \%$ and pressure has been maintained at 1445 psi by an active water drive. If expectations are met, the well will pay out in less than 1 year and continue on production for at least 5 years. Cronus Development Co. is tentatively planning to drill three more horizontal wells in the Dundee in Crystal Field. Thus, the play concept we chose to test, that bypassed attic oil remained in the Dundee reservoir between wells that had been produced at excessively high flow rates and had coned water during primary production, appears to be correct, and the TOW No. 1-3 HD-1 well is now a scientific, and appears soon to become an economic, success.

We will soon acquire several existing seismic lines in the Crystal Field area and have been offered free processing of the lines by a commercial vendor. This data will add a significant dimension to our study.

\section{CORE AND LOG ANALYSIS}

Well-log analysis and regional geological studies are being carried out by $W$. Harrison and his graduate students at WMU. Well data, including drillers' logs and wireline logs for the 8526 wells in our seven-county study area (Fig. 1), which includes 4785 wells that penetrate the Dundee, were acquired from Maness Petroleum Co. and are now in our oil and gas well data set (Table 1). Formation tops have been picked for all formations in all wells. Maps and cross sections have been completed for Crystal Field and for the 30 other Dundee oil fields in the study area. All these maps have been plotted on $81 / 2 \times 11$ pages and have been assembled by field into single "folio" sized poster sheets (Figs. 2, 3). These maps and cross sections are currently being compiled into notebooks for each field, along with field and reservoir data, field production histories and decline curves, type logs, and core data. These notebooks will be combined with an overview and summary evaluation volume to form an "Atlas of Michigan Dundee Reservoirs" (see discussion under "Dundee Atlas"). Basin-scale maps and cross sections are being prepared in the GeoGraphix Exploration System at MTU (Fig. 4).

Well-log analysis using TerraSciences TerraStation software is continuing. Lithologies and water saturations continue to be calculated for selected wells in the 30 fields in our seven-county study area using density/porosity and Pickett crossplots (Fig. 5, 6).

Digitized logs were loaded into the GeoGraphix Exploration System well-log package QLA2 and a few trial log cross sections were constructed.

Well-status and production-decline curves were prepared for all 30 study fields (Figs. 7, 8). Decline curves are proving to be a very useful tool for identifying fields that have significant remaining unrecovered oil and are good candidates for enhanced oil recovery programs. 


\section{Winterfield Field}

S. Chittick has completed his M.S. thesis on Winterfield Field, which possesses more modern log data than most other Dundee Fields. In Winterfield Field, several wells penetrate the entire Dundee porosity zone, allowing a more thorough evaluation of the reservoir than could be done elsewhere. The purpose of the Winterfield study was to delineate possible economic zones of by-passed oil in the Dundee by characterizing the structural, stratigraphic, and lithological components of the Dundee utilizing well data (drillers' logs and scout tickets), petrophysical log data, and production data.

Cross sections of Winterfield Field illustrate the extreme variability in production that is so characteristic of these Dundee fields and show how the Dundee porosity zone varies in thickness across the field. The top of dolomite porosity drops below the oil/water contact in places, leading to discontinuities in the reservoir which may result in bypassed oil. Thus, understanding Dundee dolomitization is important to enhanced oil recovery operations.

Chittick's M.S. thesis represents a major technical contribution of this project.

\section{CORE ACQUISITION AND ANALYSIS}

The TOW No. 1-3 HD-1 well in Crystal Field (our DOE project well) was spudded on September 20, 1995 and cored and logged through the Dundee. One and one half weeks later, $59.3 \mathrm{ft}$ of core was recovered from the top of the Dundee and the well was then drilled $150 \mathrm{ft}$ below the base of the core to TD at the top of the Detroit River anhydrite. The vertical well was then logged from TD at the base of the Dundee ( $3334 \mathrm{ft}$ ) to the base of casing ( $683 \mathrm{ft}$ ), which corresponds approximately to the base of the glacial till. Haliburton ran 3 consecutive log suites, which included: 1) a gamma ray and dual laterolog with microresistivity, 2) a lithodensity $\log$ (compensated formation density plus photoelectric factor), and 3) a compensated neutron log (Fig. 9). The logs were then correlated with a high degree of confidence and combined. The top portion of the Dundee displayed good oil staining in the core. Therefore, the log suite has good coverage of both the oil leg and the water leg in the Dundee Formation. This was later confirmed by residual fluid saturation analyses of core samples.

The uppermost Dundee reservoir was cored in the TOW No. 1-3 HD-1 well. The coring point was in the lowermost Bell Shale, immediately above the Dundee. $59.3 \mathrm{ft}$ of core were recovered out of a possible $60 \mathrm{ft}$ (Fig. 10). The core was shipped to OMNI Laboratories in Houston where a core gamma ray log was run and the core was photographed under plane and ultraviolet light to reveal sedimentary structures and heterogeneities in oil saturation. Porosity, permeability, and residual fluid saturation analyses were performed on whole-core samples taken at $1 \mathrm{ft}$ intervals. 
Dolomite extends almost to the top of the Dundee, and the nonporous cap limestone, which is normally $10-15 \mathrm{ft}$ thick in much of Crystal Field, is only $2 \mathrm{ft}$ thick in the TOW No. 1-3 well. The upper $15 \mathrm{ft}$ of the Dundee is heavily fractured in core and contains centimeter-sized vugs. Most fractures are subvertical with highly variable azimuths, but some fractures are developed at lower angles. Most fractures and vugs are lined with white, sparry dolomite. The top of the Dundee in the demonstration well was encountered $8 \mathrm{ft}$ lower than projected. Together, these observations suggest that a top-down solution process (karst?) led to fracturing and collapse of the uppermost Dundee, which resulted in development of enhanced porosity.

Twenty nine feet of higher residual oil saturations at the top of the Dundee (3190-3219 ft) in the core indicate significant unrecovered oil. Beneath that, seven feet of lower residual oil saturations (3219-3226 ft) indicate either a transition zone or a swept zone where the oil-water contact moved up as a result of primary oil production. In the water leg below $3226 \mathrm{ft}$, residual oil saturations are $0.0 \%$ (Table 2).

In February, 1996, W. Harrison and J. Allan examined the TOW No. 1-3 core and identified several mudstone-to-grainstone hemicycles, which range in thickness from 5 to $15 \mathrm{ft}$. The grainstones appear to be leached and have high porosities and permeabilities. They may account for a large proportion of the reservoir volume. More importantly, most open fractures are subvertical and are confined to the top of the reservoir, while grainstone beds may form sheet-like fluid-flow conduits that extend down to the oil/water contact. These high permeability grainstones, rather than fractures, may be responsible for the early watering out of many wells. Core samples were collected for thin section, stable isotope, and fluid inclusion analysis. Allan and Harrison will undertake a detailed core study this summer.

During the first quarter of 1996, K. Moss and two other staff members from Western Atlas spent two days at MTU discussing the Crystal Field well, logging techniques, and, in particular, use of the Circumferential Borehole Imaging Log (CBIL) with W. Pennington and other faculty and graduate students. We may arrange to run a borehole imaging log (which is excellent for identifying fractures and vugs) in one of the upcoming Crystal Field wells.

About 50 cores of the Dundee Formation from throughout the state of Michigan have been identified and are currently available in public repositories (i.e., the Western Michigan University Core Research Lab, the University of Michigan Subsurface Lab, the Wayne State University core facility, the Central Michigan University core facility, and the Michigan Geological Survey core repository in Lansing). Selected cores will be described and samples will be taken for thin section, Xray diffraction, and SEM analyses to determine mineralogy and porosity characteristics. Cuttings samples from 60 to 100 Michigan wells are also available. In February 1996, Harrison and Allan examined core from four Dundee fields and one off-structure well near Crystal Field and collected samples for thin section, stable isotope, and fluid inclusion analysis. 


\section{Fourier Transform Infrared Spectroscopy (FTIR)}

FTIR spectral analyses and Inductively Coupled Plasma Spectroscopy (ICP) chemical analyses were collected on a suite of mineral standards by graduate student N. Popko. Data reduction was recently completed. Spectral data from standards were input to MatLab, a numerical computation and visualization software package, which was then used to generate non-negative least-squares (NNLS) fits to the data. ICP elemental analyses were converted to oxides, and mineralogies were calculated and used to crosscheck the FTIR results. The FTIR technique will next be used to analyze Dundee core samples. Popko is doing this work as his Master's research under the direction of W. Pennington.

\section{Fluid Samples}

Hydrocarbon and produced-water samples will be collected from the demonstration well in Crystal Field. If possible, arrangements will be made to sample fluids from other Dundee fields as well. Inorganic geochemical analyses of produced brines will be used in conjunction with isotope and fluid inclusion analyses of core and cuttings to determine the origin and history of the porosity-producing dolomitizing fluid..

\section{DATABASE MANAGEMENT}

Microsoft Access is our relational database management platform. All of the log data are stored in Access in LAS format. All other data are stored in Toolbook, (a Multimedia archive and display program), and are accessible via pulldown menus and a Table of Contents with hot links. Instructions for retrieving logs from the Access database are included in the Toolbook multimedia archive. Users can search the database by query and retrieve the logs from the main database table by well or by $\log$ type. Logs are then placed in smaller temporary Access tables from which they can be exported to applications programs.

Currently, project personnel at WMU are using TerraSciences' TerraStation software to analyze and archive project data, while the MTU group is using the GeoGraphix Exploration System to analyze project data.

The GeoGraphix Exploration System software package was acquired in fall 1995 and installed on a PC in the Subsurface Laboratory at MTU. Since that time, we have acquired an academic license and three additional seats on GeoGraphix. Graduate students S. Chittick and W. Everham attended a training course at GeoGraphix' headquarters office in December and professor J. Huntoon and graduate student W. Houston attended in February. W. Pennington arranged for MTU to get three additional seats on GeoGraphix for free, as part of the company's academic incentive program. We now have four Dongal keys to GeoGraphix and can run the program at multiple sites, which will greatly enhance progress. Graduate student S. Chittick worked all summer loading logs, formation tops, and other data into the program and getting the system 
operational. Well location data was input from the 51,359-well database that we acquired from Angstrom Precision this summer. Dundee tops and initial production (IP) data for Winterfield Field were input and 3D surface visualizations of structure and production data were constructed for the Dundee reservoir. Tops for the other 30 fields in the study were also loaded into GeoGraphix.

The USGS Digital Land Grid was also acquired. This data set contains surface data, such as the locations of roads, rivers, towns, etc., for the entire United States. All data for Michigan was input to GeoGraphix and is now available for use.

Chittick has begun working on a doctoral dissertation under the direction of $\mathrm{W}$. Pennington. An important component of his doctoral study will be to determine whether structural deformation in our study area is reflected in gravity maps. In pursuit of this study, he acquired the National Geophysical Data Center's Gravity Data CD ROM and loaded the Michigan portion of the data set into GeoGraphix. Bouguer anomaly and second-derivative contour maps were constructed and displayed at several scales, including the state, seven-county study area, and field levels.

A data set containing over 77,000 geochemical analyses of brines from wells throughout the United States, was acquired from a commercial database vendor. The commercial database was organized and input to our Microsoft Access database by C. Asiala and the well locations for all Michigan wells which contain brine analyses were plotted on a basemap using GeoGraphix.

W. Everham and $M$. Slis have been highgrading and editing the Angstrom database. They created a new database composed of the deepest well in each section in the state of Michigan. This reduced the number of working wells from over 50,000 to about 10,000 , while still providing sufficient information to produce the necessary stratigraphic and structural framework for our modeling effort.

\section{DRILLING}

The TOW No. 1-3 well was cored through the upper $60 \mathrm{ft}$ of the Dundee Formation, drilled to the base of the Dundee, and logged from the base of the Dundee to the base of the glacial till. During drilling through the Dundee, several lost-circulation events were experienced. The well was then cemented and plugged back to the top of the Traverse Lime and a 10 in. directional wellbore was drilled on the curve to convert the vertical well to a horizontal one. It took three days and 600 vertical feet to drill the curve and when the horizontal leg entered the Dundee, it was $400 \mathrm{ft}$ laterally distant from the original intercept of the vertical well with the top of the Dundee. The curve was then lined with 8 $5 / 8$ in. casing and drilling of the $77 / 8$ in. horizontal leg commenced. A Measurement While Drilling (MWD) gamma ray log was run to monitor orientation of the horizontal leg. 
A horizontal leg of $1800 \mathrm{ft}$ was planned (Fig. 11), but $90 \mathrm{ft}$ into the horizontal leg, the well encountered a pocket of high porosity (probably vugs and fractures) and a major lostcirculation event ensued. The well blew out, but was quickly brought under control by blowout preventers. At the time that circulation was lost, the well was being drilled with a mud capable of holding $1500 \mathrm{psi}$. Because of the high reservoir porosity, permeability, and pressure and the propensity to lost circulation in the area penetrated by the horizontal wellbore, it was decided to suspend horizontal drilling and to complete the well in the Dundee

\section{TOPICAL REPORTS}

W. Harrison has collected reservoir data for the 30 fields in our study area and is organizing and reformatting it into tables of reservoir parameters for the Topical Reports required by DOE and for inclusion in our "Atlas of Michigan Dundee Reservoirs" (see below). As he completes each field, he is forwarding the data to C. Asiala who is enters it in our Microsoft Access database. It will be eventually input to the Toolbook Multimedia Database Management System and written to CD ROM.

\section{DUNDEE ATLAS}

We plan to create an "Atlas of Michigan Dundee Reservoirs", using our maps and cross sections as a cornerstone of the publication. As envisioned, this Atlas will include a regional overview of Dundee stratigraphy and reservoir variability; development history of the trend, including comparisons between different fields; production history, including a discussion of engineering and completion techniques; and a table of important reservoir parameters for use in characterizing the Dundee reservoir in other old fields for which little data is available. The main body of the Atlas will consist of individual discussions of reservoir geology, engineering practices, and tables of reservoir parameters for each Dundee field. Discussion of the importance of fracturing, fracture density, and irregularity of the dolomitized surface will aid in the design of the optimal strategy for horizontal drilling. This Atlas will undoubtedly enhance the capability of small operators in the state to independently explore and develop this neglected resource. The Michigan Basin Geological Society has expressed interest in publishing the Atlas.

\section{PSEUDO-SEISMIC VISUALIZATION}

3-D visualizations of the Michigan Basin have been constructed in MatLab. This commercially available statistics and visualization package is flexible and powerful and can easily perform both 3-D surface and 3-D volume visualizations. M. Luo loaded the Angstrom database into MatLab and produced a 3-D volume visualization of the basin that shows the thickness and distribution of the Dundee and other key formations (Fig. 12). Cross sections can be made through the basin at any desired angle.

B. Wei is using MatLab to produce "pseudo-seismic" sections from spontaneous potential (SP) and gamma ray logs. Using Wei's program, individual pseudo-seismic logs (log 
traces whose amplitudes have been color-coded to resemble seismic amplitude traces) can easily be selected from a map-view window and displayed as well-log or pseudo-seismic cross sections (Fig. 13). This program adds another useful dimension to our visualization capabilities. Current efforts concentrate on using geostatistical methods to perform interwell correlations.

\section{MODELING}

\section{GEOCHEMICAL MODELING}

The geochemical modeling program CHILLER is being used to model fluid-rock interaction. The feasibility of porosity prediction using CHILLER is being investigated. Geochemical mass transfer work using CHILLER is being carried out by J. Suchoski. Two databases are currently being used. The thermodynamic database SOLTHERM contains thermodynamic information on fluid species, gases, and minerals. Over 400 species are contained in the database. The data are valid over a temperature range of $0^{\circ} \mathrm{C}$ to $300^{\circ} \mathrm{C}$. The database OXYBASE is being used for oxygen isotope calculations.

\section{BASIN MODELING}

The same Angstrom data set which contains information on 51,359 Michigan wells will be used both in GeoGraphix and in our basin modeling programs. The data set includes well locations, formation tops, lithologies, etc., in a form that can be read directly into our GeoGraphix Exploration System software. After solving numerous formatting problems, S. Chittick loaded the data into GeoGraphix. W. Everham and M. Slis have been correcting data errors and nomenclature problems and have drawn well-location maps in GeoGraphix which display all wells that intersect each of the deeper formations in the Michigan Basin. They have produced a more manageable data set (of 10,000 wells) by selecting the deepest well in each section in the state of Michigan. They are now constructing a grid of regional structural cross sections through the basin. The cross sections serve two purposes. First, they make it easy to spot and correct bad picks and bad data. Second, once the errors are corrected and the structural cross section grid is completed, stratigraphic cross sections, hung on key marker horizons, can be constructed. These stratigraphic cross sections will enable our project staff to visualize the evolution of 3-D basin geometry through time and focus in on the times and areas of greatest interest for geologic modeling (e.g., areas of rapid and maximum subsidence, where sourcerock maturation and oil generation are favored, should be readily apparent).

This work is being done to prepare the Angstrom data for use in the modeling programs BasinMod and Akcess.basin. BasinMod will be used for 1-D and 2-D thermal maturation modeling. Access.basin uses a finite-element formulation to examine the effects of thermal processes (conduction, convection, advection), fluid flow processes (compaction-driven, hydraulic-head driven), sealing mechanisms, and sedimentation/erosion during the development of a sedimentary basin. 
Everham is organizing the Michigan Department of Natural Resources' bottomhole temperature database for use in the modeling programs. Negotiations are still proceeding to acquire a major organic geochemistry study of the Michigan Basin, completed by Brown and Ruth Co., through donation to the project.

The Angstrom database contains lithologic information on each formation in each well. The lithologic information is now in text format, but a project to numerically encode it will soon begin. A. Wylie and one of J. Huntoon's summer students will undertake this effort. Once the lithologic data is in numerical format, it can be used in facies mapping and sequence stratigraphic modeling programs. GeoGraphix corporate management in Denver are interested in supporting this work, which will be part of Wylie's doctoral dissertation. If successful, GeoGraphix' management intends to incorporate facies mapping capability into the GeoGraphix Exploration System.

\section{TECHNOLOGY TRANSFER}

\section{PROFESSIONAL MEETINGS AND PUBLICATIONS}

\section{SEG Development and Production Forum}

J. Huntoon and W. Pennington presented posters at the SEG Development and Production Forum on "Cooperative Projects to Improve Reservoir Management" in Colorado in June, 1995. Pennington discussed the Michigan Dundee Project and another MTU DOE project involving computer visualization of reservoirs in the San Joaquin Valley, California, in which Michigan Tech is also participating. Huntoon presented a poster display on Technology Transfer. The Technology Transfer talk, entitled "Facilitating interaction between universities and industry: mechanisms for personnel and technology transfer", elicited much favorable comment. Huntoon was asked to re-present it as an invited paper at the SEG Annual Meeting. Our representatives at this meeting found it to be very successful in facilitating communication (and Technology Transfer) between various groups carrying out DOE sponsored projects.

\section{DOE Contractor Review Meeting}

J. Wood and W. Harrison attended the DOE Contractor Review Meeting in June, 1995 and presented an overview of this project and of another DOE project involving computer visualization of reservoirs in the southern San Joaquin Valley of California. Harrison presented an overview of the Michigan project and Wood presented an overview of the California project. Our Multimedia CD ROM system for archiving data and distributing project results elicited favorable comment.

\section{Professional Papers and Presentations}

In October, 1995, W. Harrison presented talks entitled "Improved Oil Recovery from Old Fields in the Dundee Formation, Michigan Basin" to the Geology Department at the 
University of Illinois-Chicago; "Improved Oil Recovery Using Horizontal Drilling in Oil Fields, Michigan Basin" to the Geology Department at Western Michigan University; and "Improved Recovery Using Horizontal Drilling in the Dundee Formation, Michigan Basin" to the Ontario Petroleum Institute in London, Ontario, Canada.

In October, 1995, S. Chittick presented a talk entitled "Characterization of the Dundee Formation, Winterfield Field, Clare County, Michigan", co-authored by S. Chittick, C. Salotti, J. Wood, W. Pennington, S. McDowell, J. Huntoon, and W. Harrison, at the AAPG Northeast Section Meeting in Schenectedy, NY.

In March, 1996, two presentations featuring project accomplishments were made at the Michigan Department of Natural Resources' Annual Symposium on "Michigan, Its Geology, Environment, and Resources". W. Harrison was the keynote speaker at the symposium luncheon and S. Chittick presented a poster session. Also in March, Harrison presented a project overview at the Petroleum Technology Transfer Council (PTTC) Regional Meeting in Grayville, $\mathbb{L}$. In April, Wood, Luo, Chittick, and Suchoski attended the Michigan Oil and Gas Association meeting in Mt. Pleasant, MI, where they informally discussed project results with members of the Michigan oil and gas community.

A paper describing the DOE Michigan Dundee project and the results of the Crystal Field demonstration well is in the final stages of preparation. It is entitled "Recovery of Bypassed Oil Through Horizontal Drilling, Dundee Reservoir, Crystal Field, Michigan" and will be submitted the Oil and Gas Journal.

\section{AAPG Computer Applications in Geology Volume}

A. Wylie and J. Huntoon are editing a volume entitled "Practical Reservoir Characterization", which is to be published as a volume in the AAPG Computer Applications in Geology series. Wylie is writing the first six chapters, which constitute a "how-to" guide to computerized reservoir characterization (Attachment 1). Seven authors have committed to contribute case studies in reservoir characterization. Each of these will be a separate chapter. One of these case studies will be a paper on the Dundee reservoir in Winterfield Field, co-authored by S. Chittick and others.

\section{Upcoming Events}

In May, W. Harrison, J. Wood, and W. Pennington will present project results at the DOE Class 2 Project Review Meeting in Midland, TX. Also in May, project members will run a booth in the Exhibit Hall at the American Association of Petroleum Geologists (AAPG) National Meeting in San Diego, CA. Tentative plans have been made to take our AAPG exhibit to the June meeting of the Michigan Oil and Gas Association. 


\section{Internet Homepage}

The Dundee Project now has its own Homepage on the Internet, which is networked to the Geology Department at WMU. It can be reached at: http://www.wmich.edu/geology/corelab/coreres.htm

\section{MICHIGAN OIL FIELD RESEARCH CONSORTIUM (MOFRC)}

Last year a newsletter was established to disseminate information on our project to the original MOFRC members and to other interested parties in the Michigan oil and gas community. Because of the MOFRC Newsletter and press releases, many people who are interested in horizontal drilling and the development of shallow shelf carbonate reservoirs, both within the Michigan Basin and in other areas, have contacted project personnel. During late 1995 and early 1996, J. Huntoon, J. Wood, W. Pennington, and W. Harrison all received at least five phone calls per week about the project. Geologists and managers from KEP Exploration of Traverse City, MI, and Richland Petroleum of Denver, CO, visited Harrison at WMU to review well results and well data. Several project members have been contacted repeatedly by Unocal staff members. (Unocal plans to drill several horizontal wells to the Dundee Formation in Porter Field in 1996). Shell-Western is now seriously interested in the Dundee play.

Companies are starting to tie up Dundee acreage, presumably as a result of the success of our project well. Several contacts were with principal officers of independent oil companies who requested information to help them initiate horizontal drilling programs. Since publication of the first MOFRC Newsletter last summer, our group has received many requests for inclusion on the mailing list.

\section{MULTIMEDIA PRESENTATIONS ON CD-ROM}

When the project is completed, our Toolbook Multimedia Database will be written to CD ROM and made available to the public.

\section{WORKSHOPS}

In January, 1996, project members from MTU and WMU held a two-day workshop at MTU to examine the core from the demonstration well, to discuss project results, and to plan next year's technical program and publication schedule. 


\section{TABLES}

Table 1. List of data contained in our oil and gas well data set (obtained from Maness Petroleum Co.). This data set contains information on 8526 wells in our sevencounty study area. Our project team recently acquired additional formation-top and lithology data for 51,359 wells throughout the state of Michigan from Angstrom Precision.

Table 2. Results of porosity, permeability, and fluid saturation analyses performed on whole-core samples taken at 1 foot intervals from cored interval in the Dundee project demonstration well. 
RESERVOIR CHARACTERIZATION OF SELECTED DUNDEE FIELDS IN THE MICHIGAN BASIN

D.O.E. CLASS II - SHALLOW SHELF CARBONATES

\section{Oil and gas well data set:}

Digital data set consists of 8526 wells with latitude and longitude locations, reference datum (usually ground elevation or Kelly bushing), formations tops from the glacial drift cover to the bottom of the hole. A total of 4785 of these wells penetrate Dundee or deeper horizons. Initial reported production is recorded for each producing well. The following maps have been produced for 30 selected fields in the Michigan basin.

1. Base map with well locations, well completion type, and permit number.

2. Structural countour map on top of Dundee Formation-subsea.

3. Structural countour map on top of porosity zone-subsea.

4. Isopach map of Traverse Limestone (unit immediately overlying Dundee Fm.).

5. Initial production contour map before stimulation treatment.

6. Initial production contour map after stimulation treatment.

7. Field map showing locations of "stick" cross sections (at least 2 cross sections per field).

8. "Stick" cross sections across the field showing top of Dundee, top of porosity zone and total depth of each well in the cross section.

\section{Well production history data set:}

This is a MIcrosoft Excel spreadsheet with annual field production statistics and well status data. The data set includes:

1. year

2. number of producing oil wells

3. number of producing gas wells

4. new wells drilled during the year

5. wells abandonded during the year

6. total annual oil production

7. total annual gas production 
This Excel spread sheet data has been loaded into a plotting software called PSI-PLOT to produce:

1. Production history curves (decline curves).

2. Well status history curves (producing wells, new wells drilled, wells abandonded).

\section{Electric log data set:}

This dataset currently contains 342 wells with various digitized log curves. The logs digitized include some or all of the following:
Gamma Ray
Density
Caliper
Neutron
Photoelectric Factor
Microsperically Focused Log
Sonic
Compensated Neutron Porosity
Dual Lateral Log
Dual Induction

Additionally, 194 more logs have been collected and will be added to this data set. These logs are mainly from older wells and are mostly Selfpotential (SP) and Resisitivity (RES) logs.

Calculations from this digital set have produced various plots of the log data including:

1. Pickett Plot for determining water saturations.

2. Porosity/density crossplots for determining lithology.

3. Digital replotting, rescaling, and normalizing various log traces.

4. Calculations of true rock (Rt) and water resisitivities (Rw).

\section{Field description data set:}

This data set contains all available information about the general geology, production practices, production history, field development, and engineering parameters for each field.

\section{Geologic samples data set:}

All available data plus new information generated during this project for 
mineralogic, petrographic, lithologic and isotopic properties of cores and samples form in and around each of the selected fields. Analyses include:

1. Core or sample (cuttings) descriptions.

2. Thin section analyses based on point counts.

3. X-ray diffraction analyses for mineralogy.

4. Scanning electron microscope imaging or grains, matrix and porosity. Energy dispersive X-ray determination of elemental compositions of rock materials.

5. Oxygen and carbon isotopic analyses of selected samples.

6. Quantitative porosity and permeability analyses (conventional core analyses). 
FILE NO: $\mathrm{H}-2633$

ANALYST MONTUPLUMLY

DATE: 5-Jan-95

CORES: CONVENTIONAL

WYHOLE CORE ANALYSIS

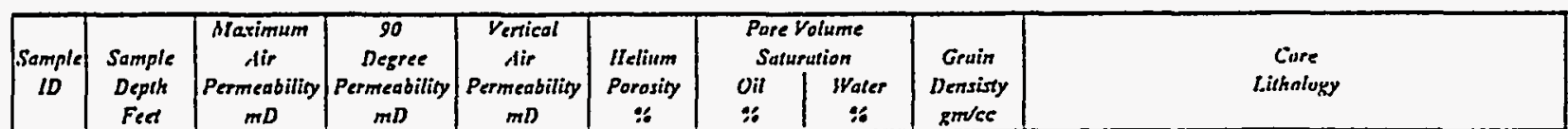

3174.86

$1 \quad 3186.87$

$2 \quad 3187.88$

3 3188-89

$4 \quad 3189.90$

$5 \quad 3190-91$

$6 \quad 3191-92$

3192.95

$7 \quad 3195-96$

$8 \quad 3196-97$

3197-98

$10 \quad 3198-99$

$11 \quad 3199-3200$

$23200-01$

$13 \quad 3201.02$

$14 \quad 3202.03$

3203-04

3204.05

3205-08

3206-07

3207.08

3208-09

$21 \quad 3209.10$

22 3210.

23 3211-12

$24 \quad 3212.13$

25 3213.14

263214.15

$27 \quad 3215-16$

$28 \quad 3216.17$

$29 \quad 3217.18$

$30 \quad 3218.19$

$31 \quad 3219.20$

$32 \quad 3220.21$

33221.22

$34 \quad 3222.23$

$35 \quad 3223-24$

$36 \quad 3224-25$

$37 \quad 3225.26$

$38 \quad 3226 \cdot 27$

$39 \quad 3227-28$

$10 \quad 3228-29$

$41 \quad 3229.30$

42.3230 .31

$43 \quad 3231.32$

$14 \quad 3232.33$

\subsection{6}

0.29

$<0.01$

0.13

$<0.01$

0.03

$<0.01$

0.06

$<0.01$

3957.

0.21

0.33

0.53

2635.

564.

9.65

2.14

792.

769.

8.23

14.0

0.32
0.42

$1.96 \quad 1.15$

0.12

3.51

235.

4.11

0.96

0.03

5.65

2.63

2.78

0.02

1.63

233.

277.

8.13

41.2

59.5

0.11

524.

$<0.01$

0.11

0.04

2.76

0.10
4.24

0.14

0.17

0.16

560.
2.65

2.09
1.62

1.62
193.

476.

1.07

7.80

0.30

0.28

\section{$<0.01$}

0.03

$<0.01$

0.03

0.12

$<0.01$

4.04

$0.11 \quad 3.3$

$2.21 \quad 2.5$

16.9

4.05

0.69

1.30

0.29

626.

835.

0.30

13.8

0.52

0.34

31.6

0.50

1.68

171.

0.44

1.77

$<0.01$

1.43

10.9

0.04

$<0.01$

0.04

16.1

30.8

0.07

18.7

63.3

0.06

10.1

$<0.01$

0.03

0.03
0.09

0.04

0.05

$0.04 \quad 5.2$

0.05

7.3

No analysis

2.97 Silt bik dol pyr

2.90 Silt blk dol pyr

2.91 Dol slty pyr sealc

2.83 Dol slly pye scaic foss no flu

2.83 Dol ssily spyr calc foss

2.83 Dol pyr calc loss

No anaylsis

2.86 Dol sshy vug vt frac scalc

2.86 Dol svug vi frac scalc loss

2.84 Dol ssily svug vt frac scalc

2.82 Dol vug vi irac scalc

2.84 Dol sshy svug vi frac scalc

2.84 Dol vug frac scalc

2.83 Dol ppvug scalc loss

2.85 Doi vug foss

2.83 Dol vug seale foss

2.84 Dol svug foss

2.83 Dol svug vt frac scalc foss

2.83 Dol svug scale foss

2.82 Dol suug vi frac scalc loss

$18.9 \quad 12.6$

2.83 Dol vug vt trac scalc

2.84 Dol svug vt frac

2.83 Dol sshy vi frac sty foss

2.83 Dol vug foss

2.85 Dol vug foss

2.85 Dol suug vi frac

2.85 Dol sslfy svug sfrac

2.82 Dol vug vi frac

2.84 Dol svug vi frac

2.85 Dol svug loss

2.81 Dol ppyug loss

2.82 Dol svug vt frac

2.85 Dol vug vt frac scalc

2.82 Dol vug vt frac

2.80 Dol veg vt frac siy

2.83 Dol svug vt frac

2.85 Dol svug frac

2.82 Dol vug strae spyr seale

2.82 Dol vig frac sealc

2.80 Dol suug vi irac

2.83 Dol

2.85 Dol svug lrac

0.0

2.82 Dol svug sfrac

2.82 Dol vug

Table 2 Results of porosity, permeability, and fluid saturation analyses performed on whole-core samples taken at 1 foot intervals from cored interval in the Dundee project demonstration well. 


\section{FIGURE CAPTIONS}

Figure 1. Basemap showing locations of Crystal Field and the 29 other fields in which the Dundee reservoir is being characterized in the project's seven-county study area.

Figure 2. Structure contour map, top Dundee Formation, Crystal Field, Montcalm County, MI, showing location and original trajectory of the TOW No. 1-3 demonstration well.

Figure 3. Initial production (IP) contour map, Dundee reservoir, Crystal Field, showing location and original trajectory of the TOW No. 1-3 demonstration well. Note that location was chosen in an area with high IP's, where wells produced at several thousand BOPD, but generally watered out quickly.

Figure 4. North-South structural cross section through Michigan Basin constructed in GeoGraphix using Angstrom Precision's database.

Figure 5. Density-porosity crossplot, Dundee reservoir, Smith 1-17 well, Crystal Field. Logs of selected wells from the 30 study fields are being analyzed for lithology and porosity at WMU using TerraSciences TerraStation software.

Figure 6. Pickett crossplot, Dundee reservoir, Smith 1-17 well, Crystal Field. Logs of selected wells from the 30 study fields are being analyzed for lithology and porosity at WMU using TerraSciences TerraStation software.

Figure 7. Well-status plot for Crystal Field. Note that field was rapidly developed after discovery, but most wells watered out in a few years due to poor reservoir management techniques.

Figure 8. Production decline curve for Crystal Field. Note extremely rapid production decline due to poor reservoir management. Decline curves are proving to be a very useful tool for identifying Dundee fields that have been badly managed and contain significant remaining unrecovered oil, making them good candidates for enhanced oil recovery programs.

Figure 9. Diagram showing wireline log traces for vertical borehole through Dundee Formation and trajectory of horizontal leg, as it was actually drilled, in TOW 1-3 well.

Figure 10. Core-description log for cored interval in TOW 1-3 well. 
Figure 11. Cross section of Dundee Formation, Crystal Field, showing planned trajectory of horizontal leg of demonstration well. Cross section was constructed before TOW 1-3 well was drilled. Wells on either side of horizontal well trajectory are projected onto plane of cross section. When TOW 1-3 well was drilled, the cap limestone was absent and the top Dundee came in lower than shown here at the location of the vertical borehole.

Figure 12. 3-D volume visualization of the Michigan Basin prepared in MatLab. The lower surface is the top Silurian. The Dundee Formation, Bell Shale, and Antrim Shale are shown above the Silurian surface. North is to the right along the $\mathrm{X}$-axis.

Figure 13. "Pseudo-seismic" display through a portion of the Michigan Basin constructed in MatLab using gamma-ray logs. Individual "pseudo-seismic" logs can be selected from wells displayed in a map view on the computer screen simply by drawing a section line on the screen. Logs of wells along the section line are then displayed in cross section, with amplitudes color-coded according to amplitude, as shown here. 


\section{DOE CLASS II FIELD DEMONSTRATION PROJECT FIELD LOCATIONS}

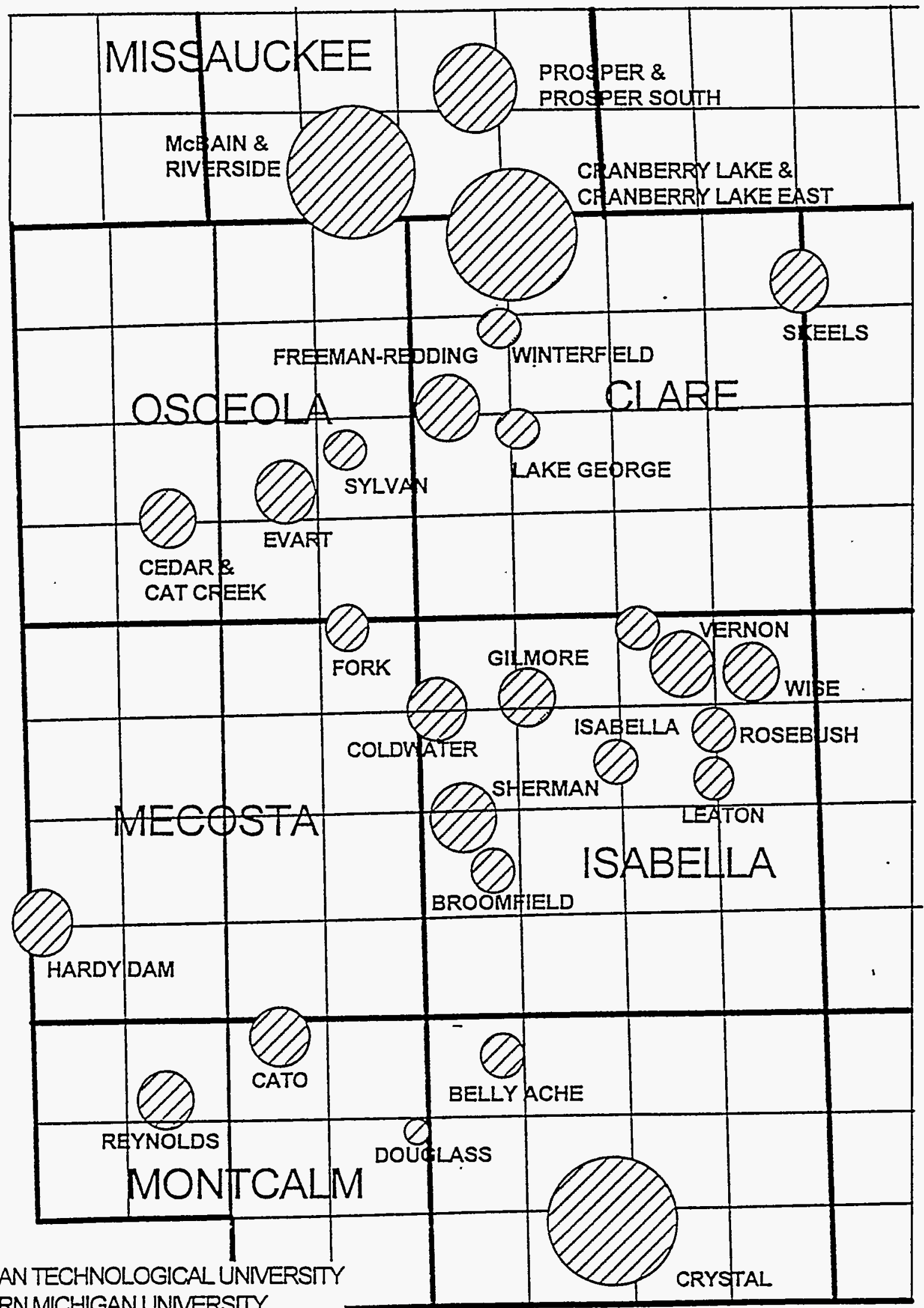

WESTERN MICHIGAN UNNERSTYY

TERA ENERGYNC., TRAVERSE CTYY MI

Figure 1 


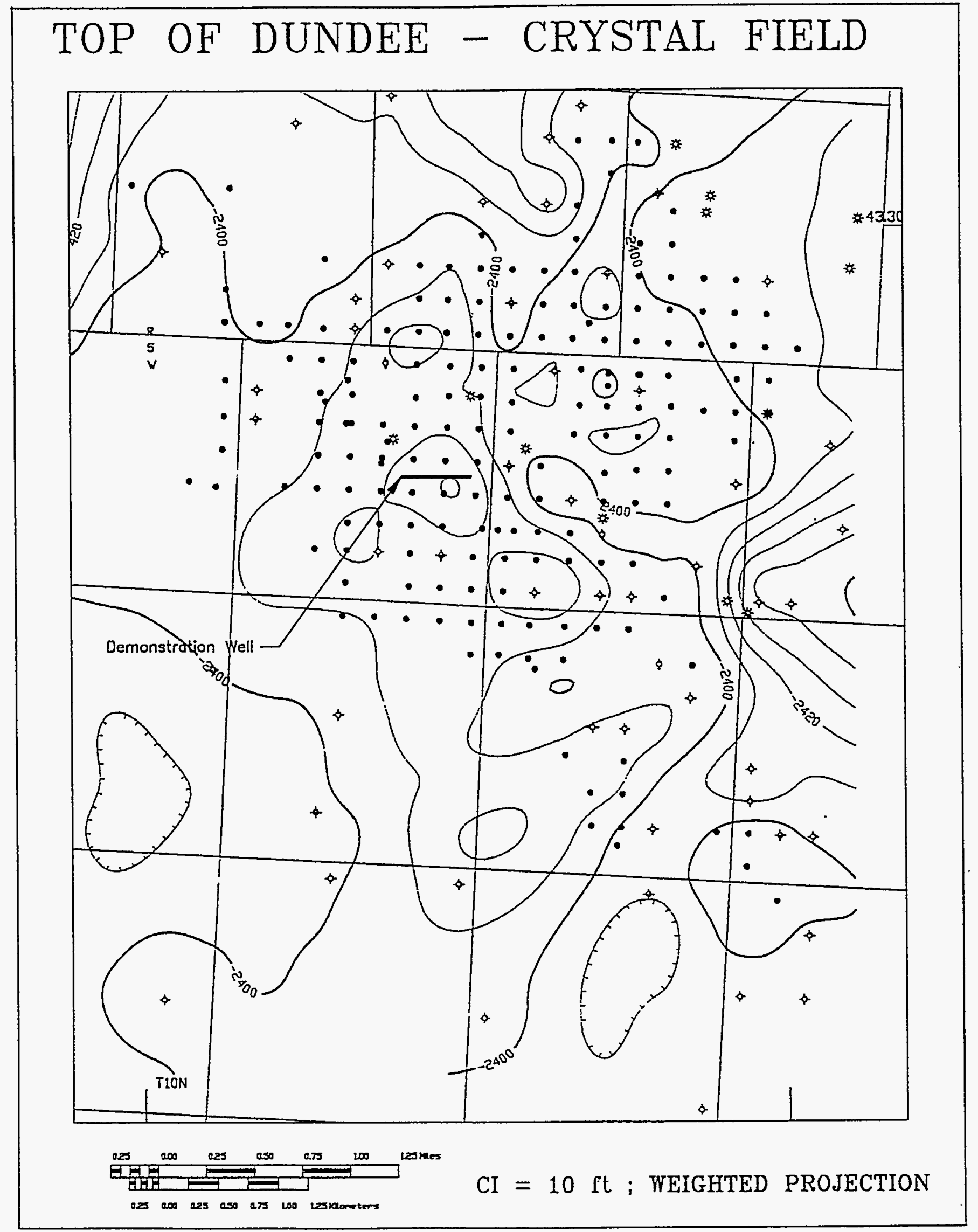

Figure 2 


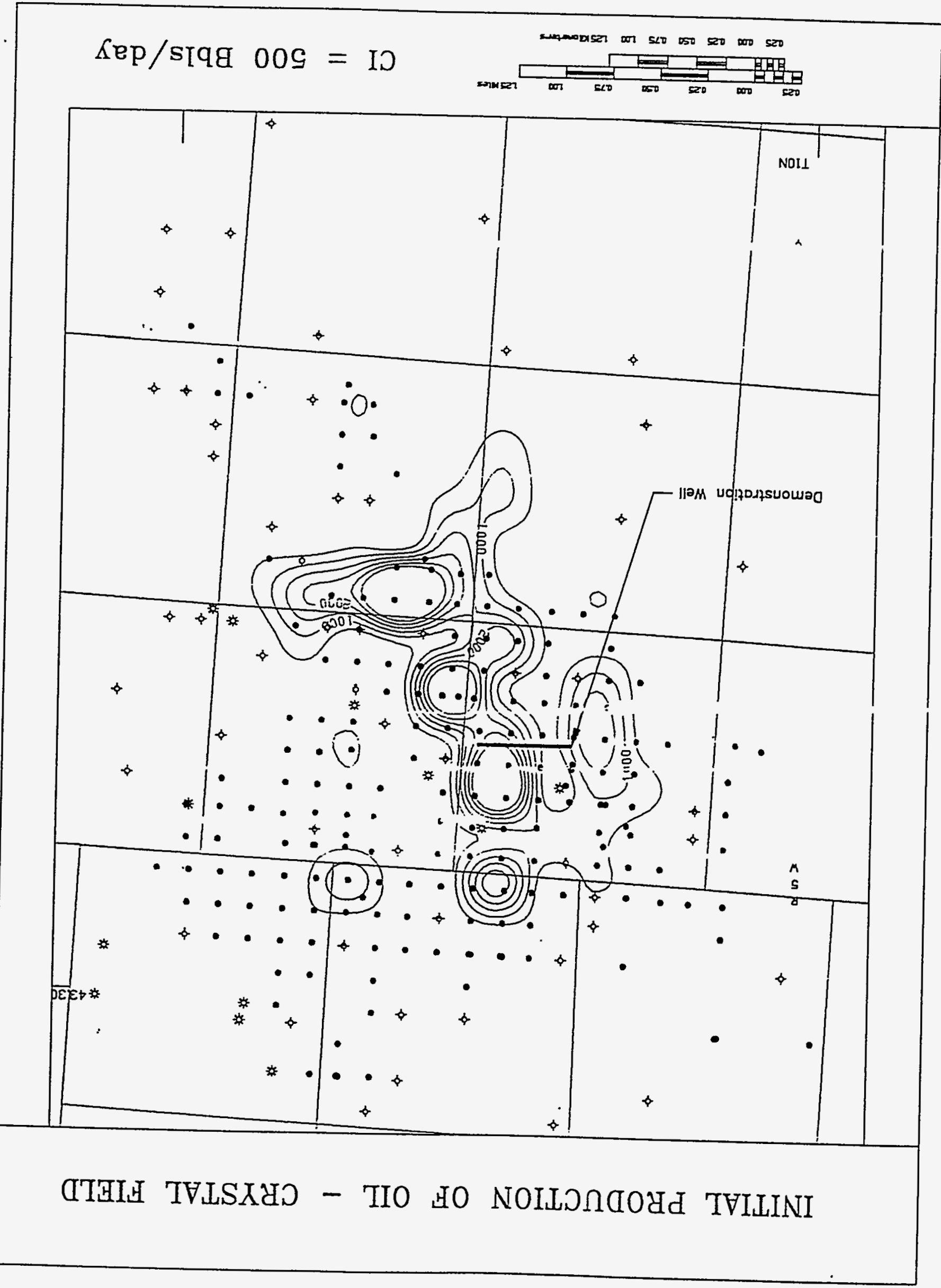



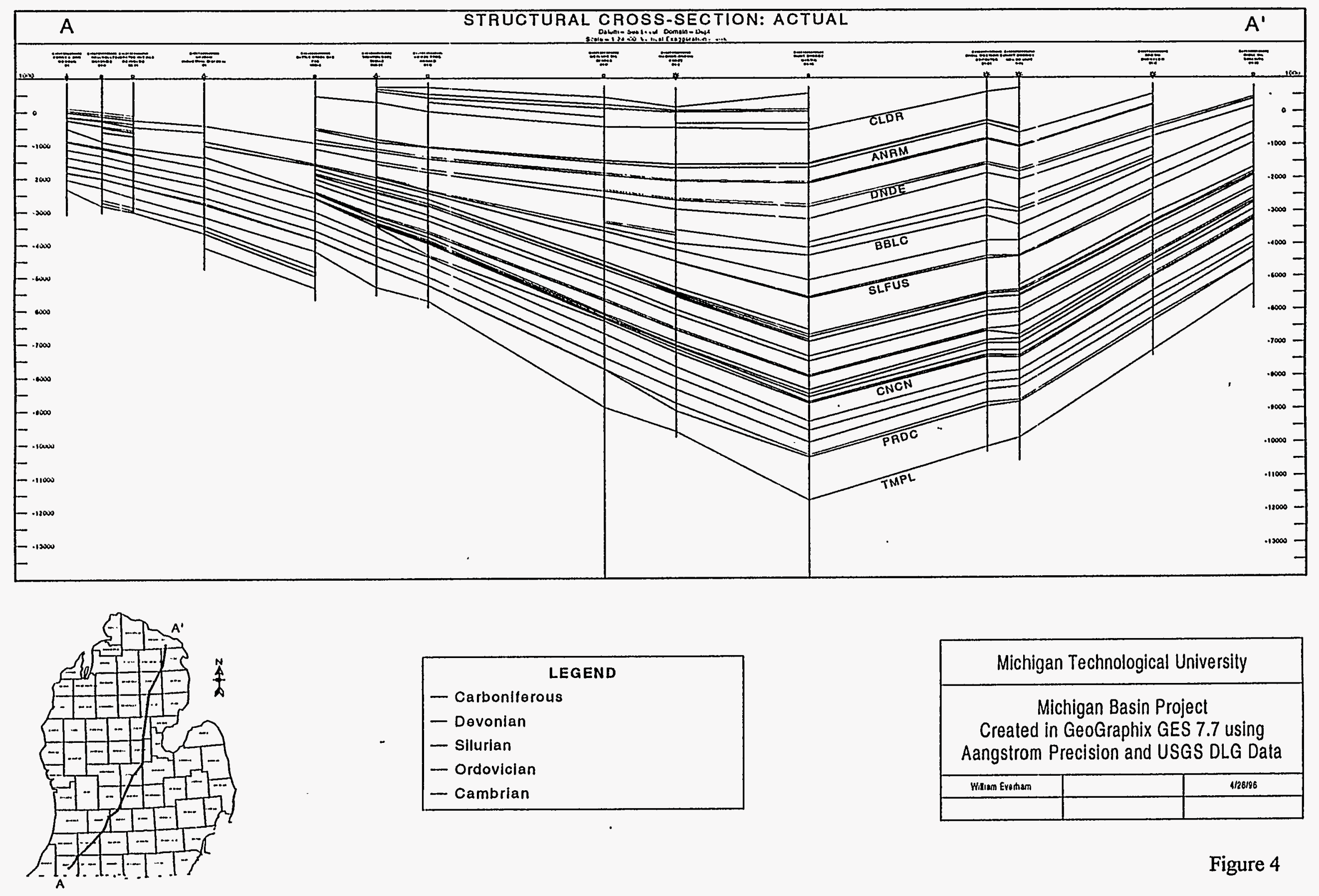

\begin{tabular}{l} 
LEGEND \\
- Carbonlferous \\
- Devonian \\
- Silurian \\
- Ordovician \\
- Cambrian \\
\hline
\end{tabular}

Michigan Technological University

Michigan Basin Project

Created in GeoGraphix GES 7.7 using Aangstrom Precision and USGS DLG Data

\begin{tabular}{|c|c|c|}
\hline Whiliam Erotian & & N/28195 \\
\hline & & \\
\hline
\end{tabular}

Figure 4 


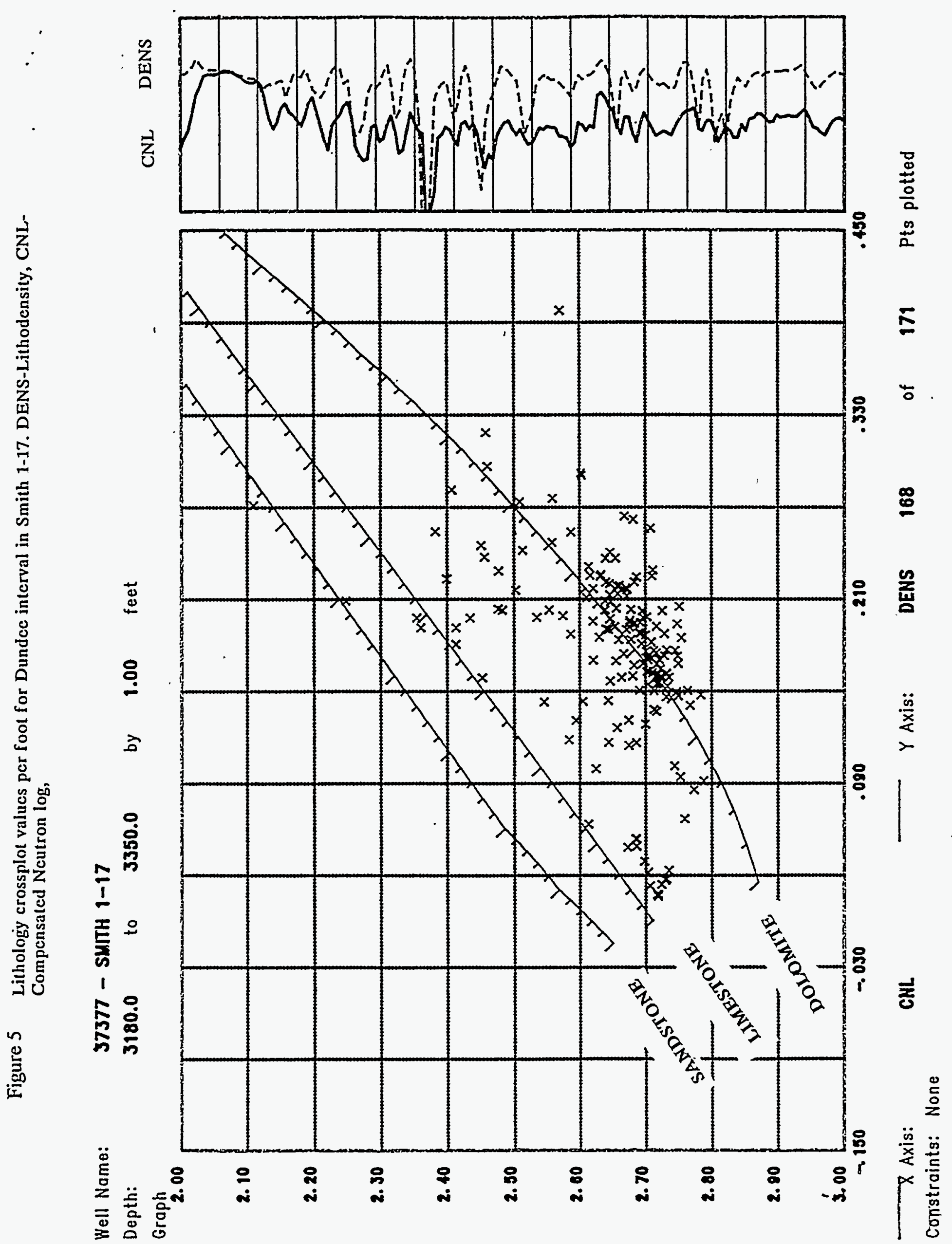




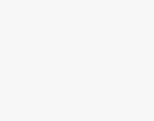

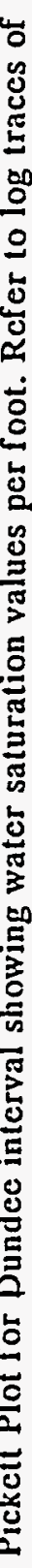

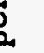
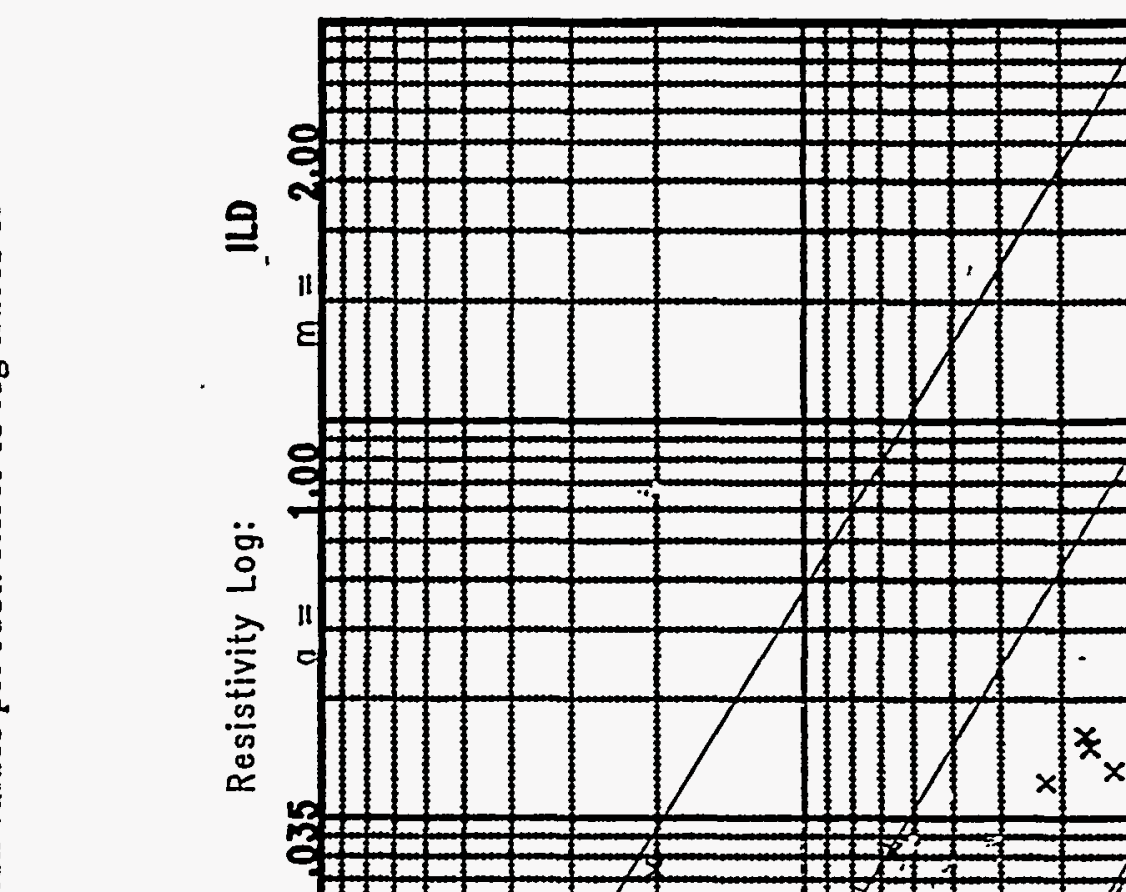

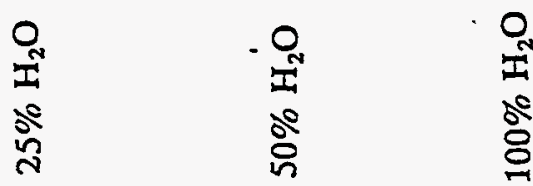
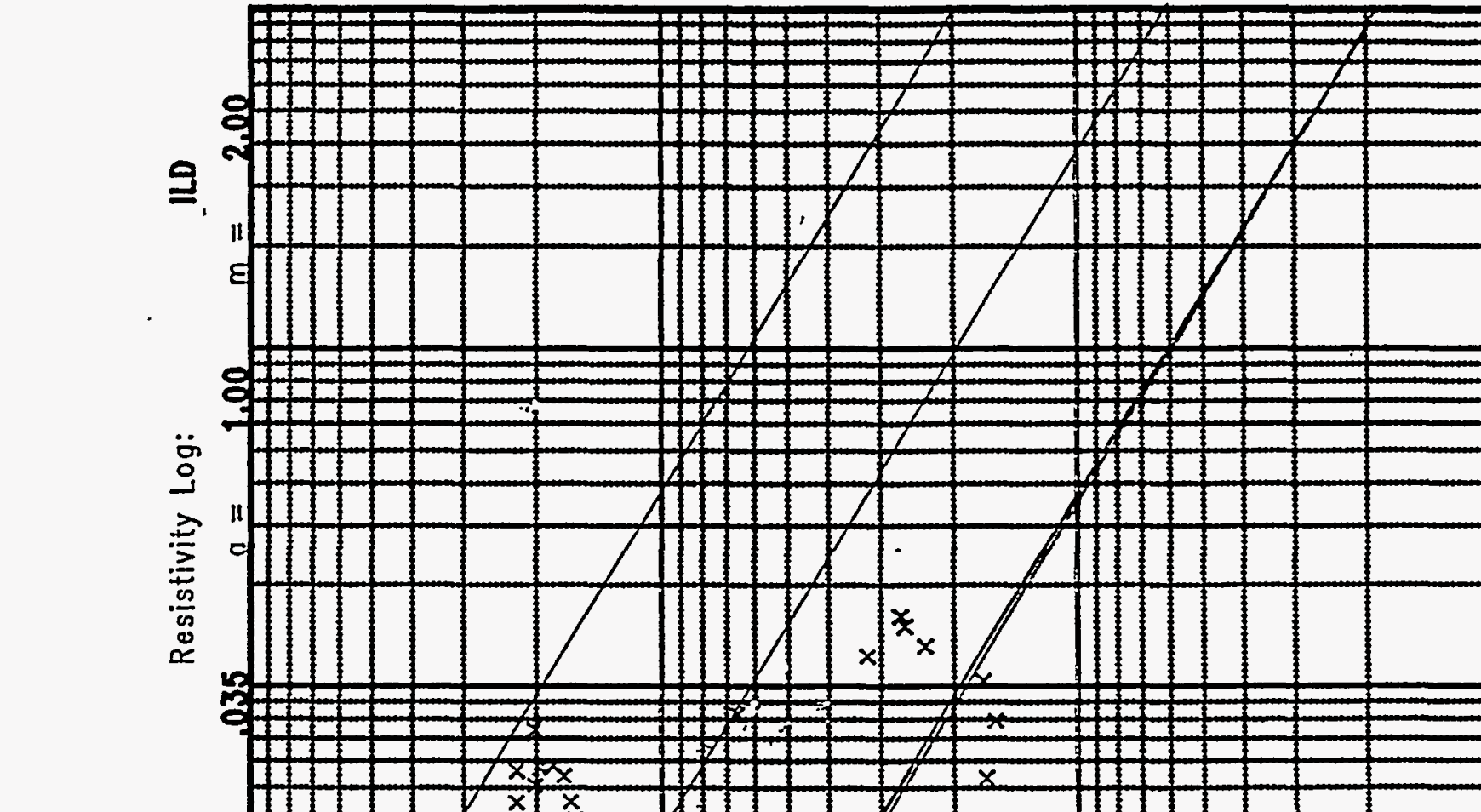

$\sum 0$

- HIf

$x^{3} \times$
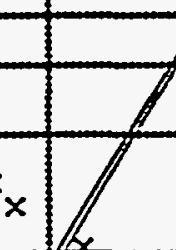

171 : $:$
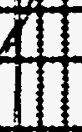

商

身

우
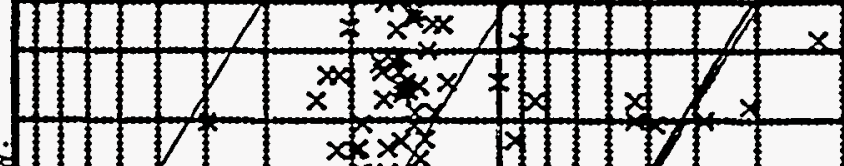

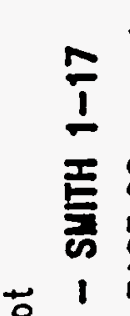

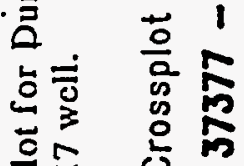

12

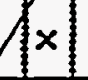

$x \times x$
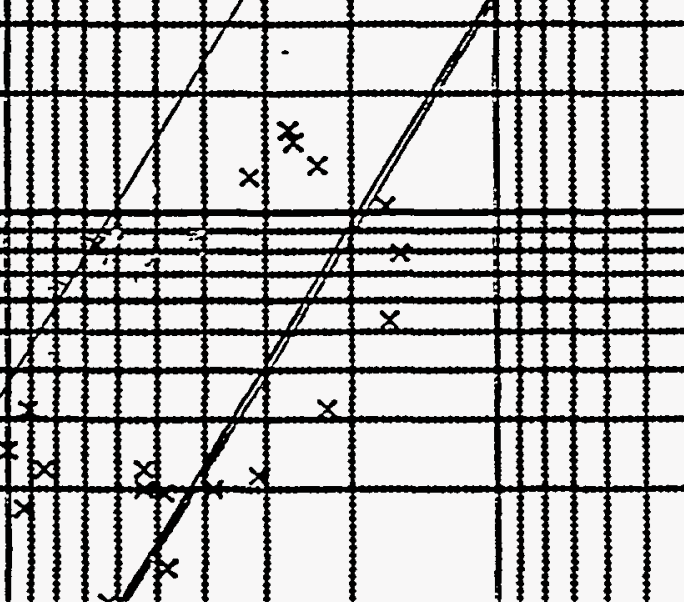

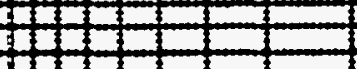

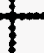

IIIII
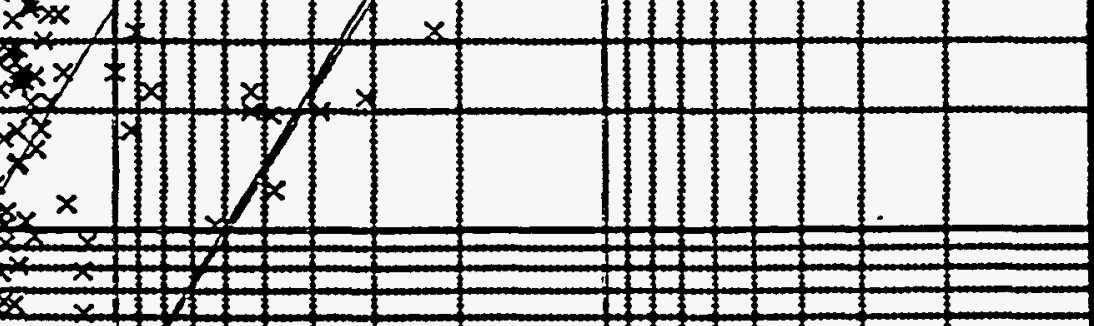

옹 官

$7 \%$

$x$

충

잉

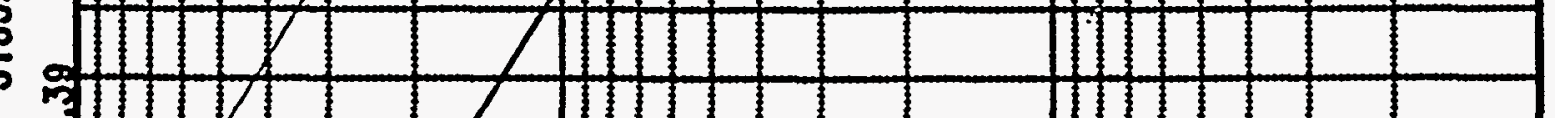

立

항

11
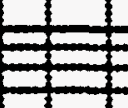

1

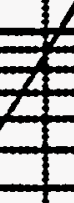
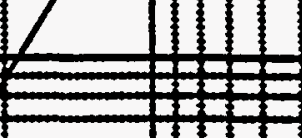

IIt 1

III: 12

응 䒛

0

1

尊兽

$9+12$

1/

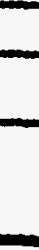

$\frac{1}{4}$

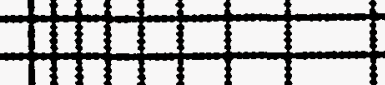

!

$\frac{0.0}{x}$

$\frac{.0}{20}$

뭉

$\frac{0}{x}$

可

촌 


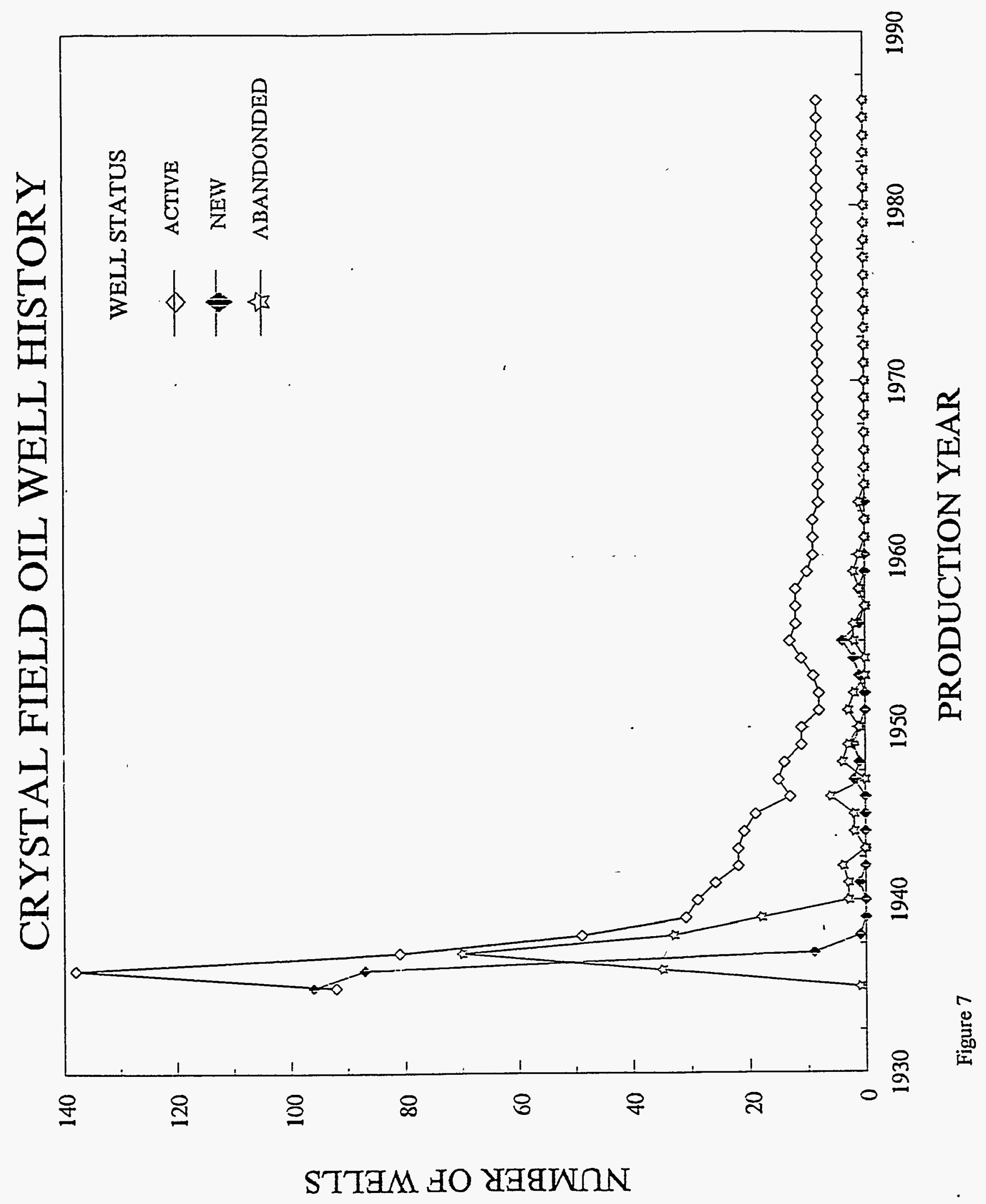




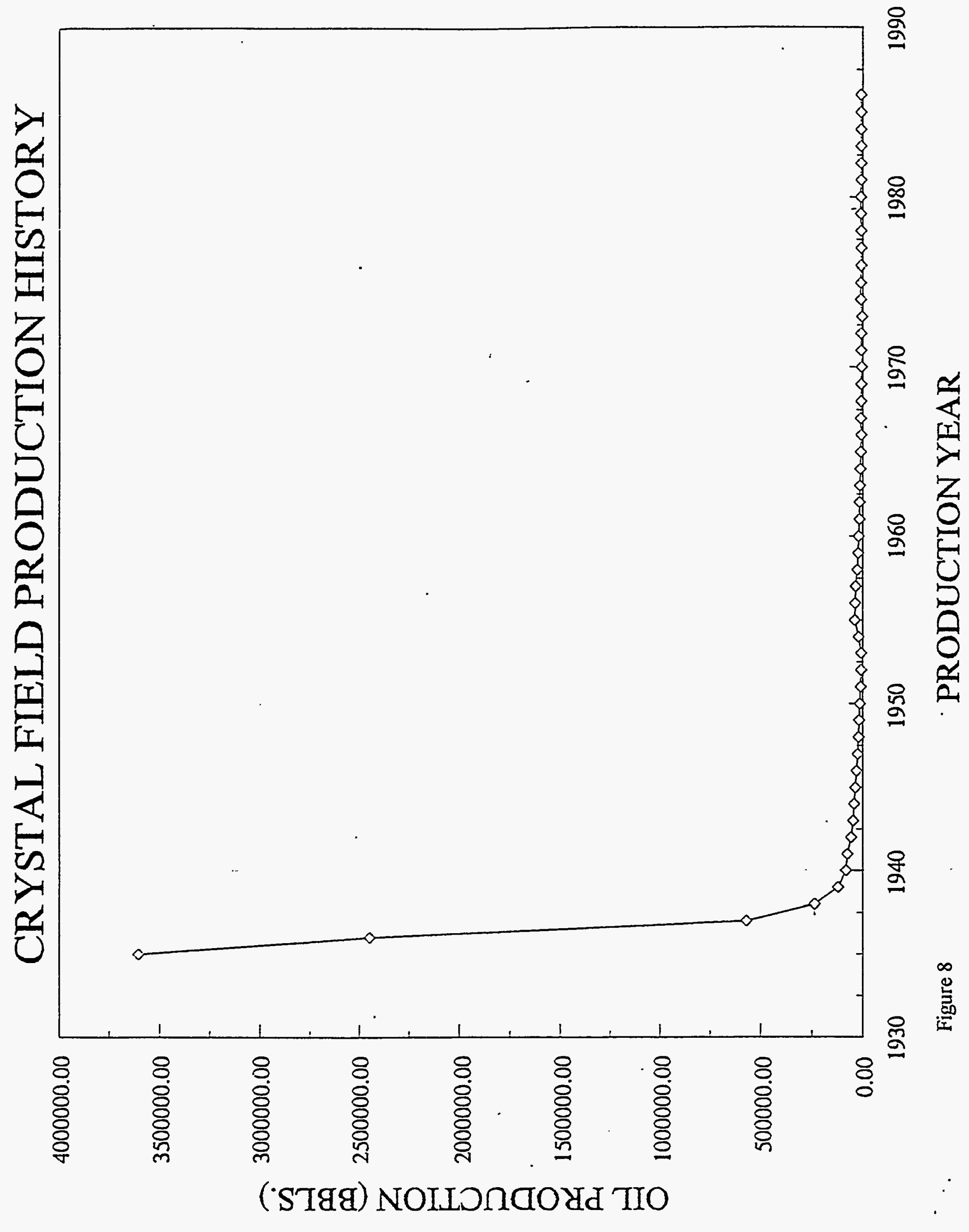




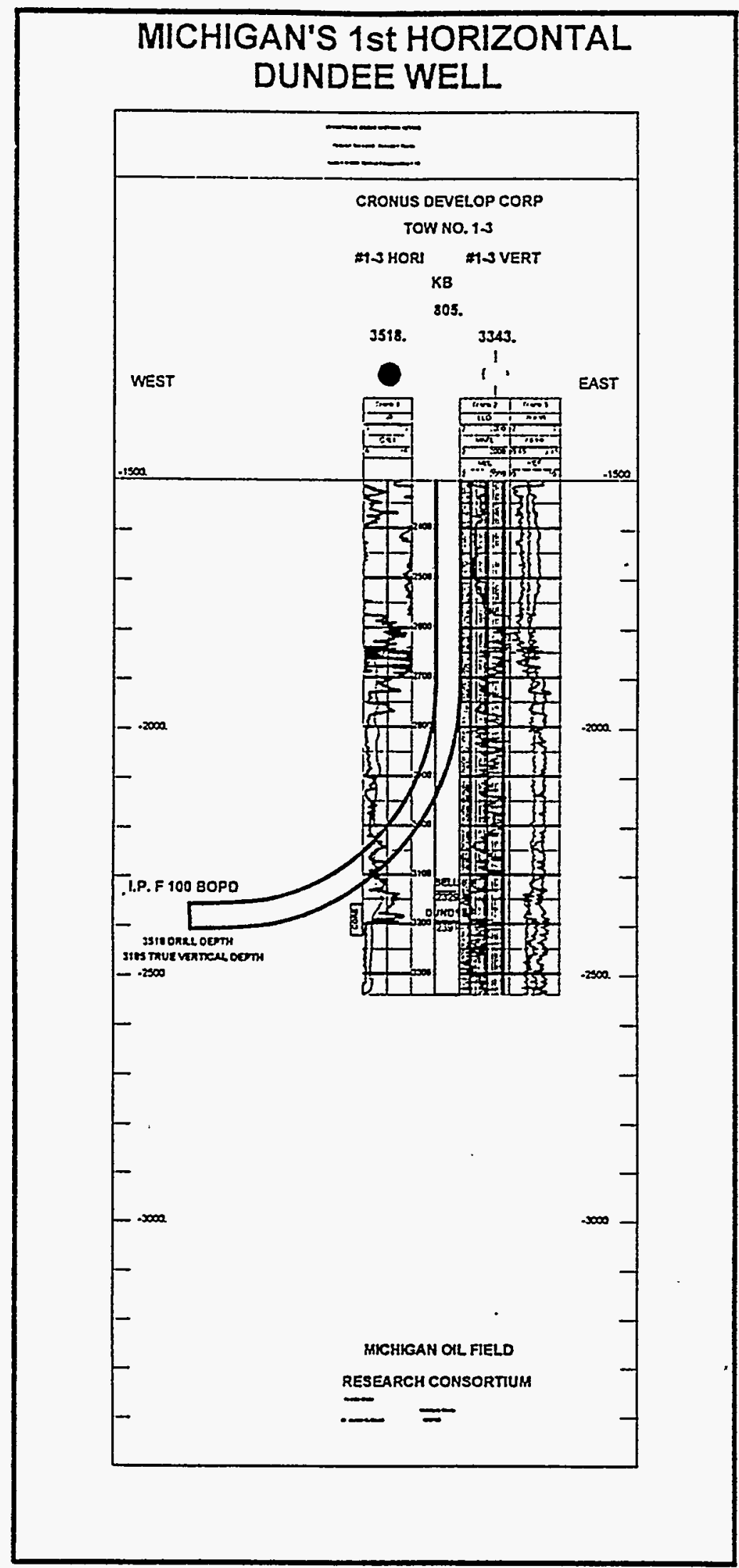

Figure 9 Diagram showing wireline log traces for vertical borehole and trajectory of horizontal borehole in Dundee project demonstration well. 


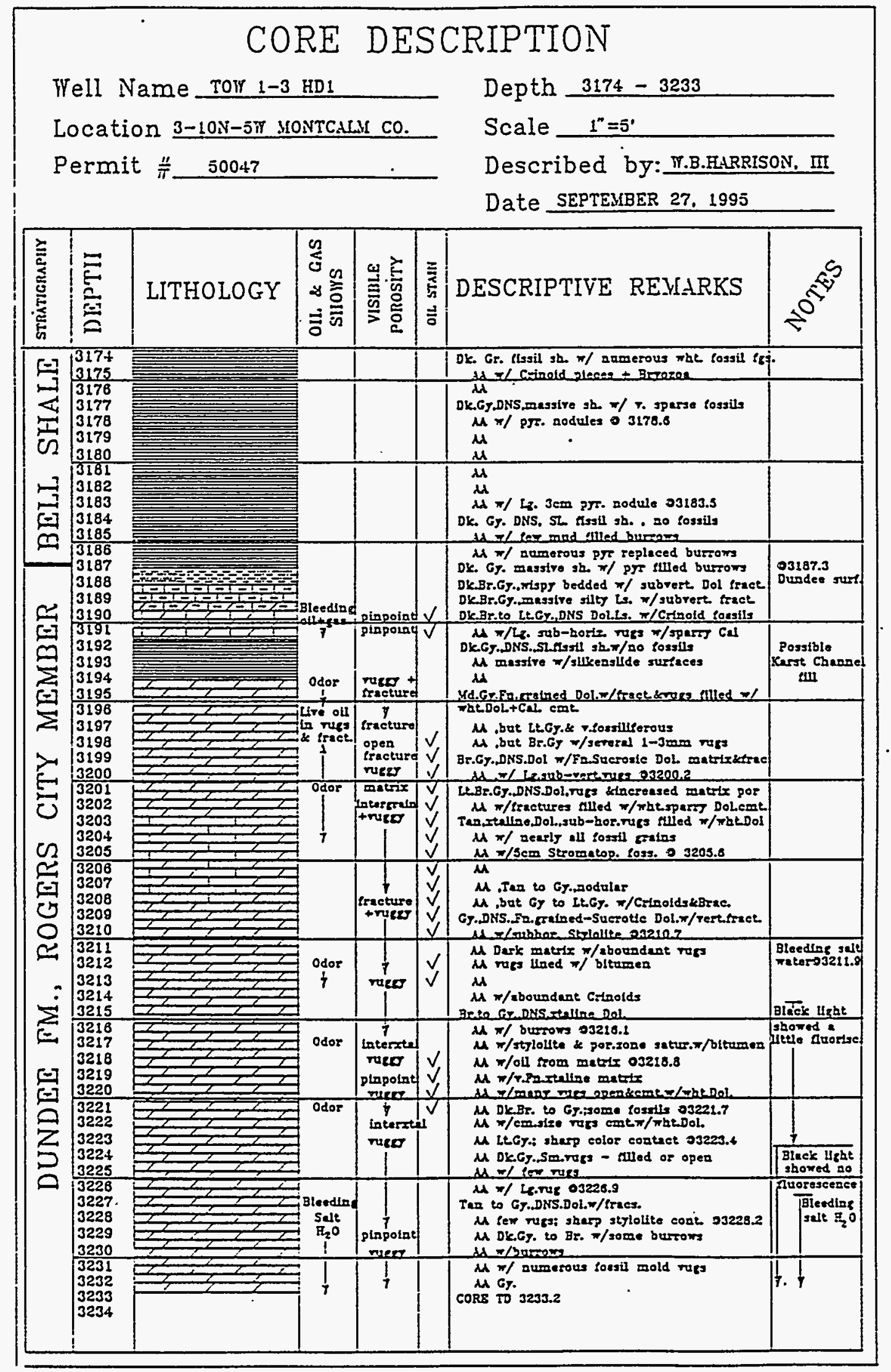

Figure 10 Core-description log for cored interval in Dundee project demonstration well. 


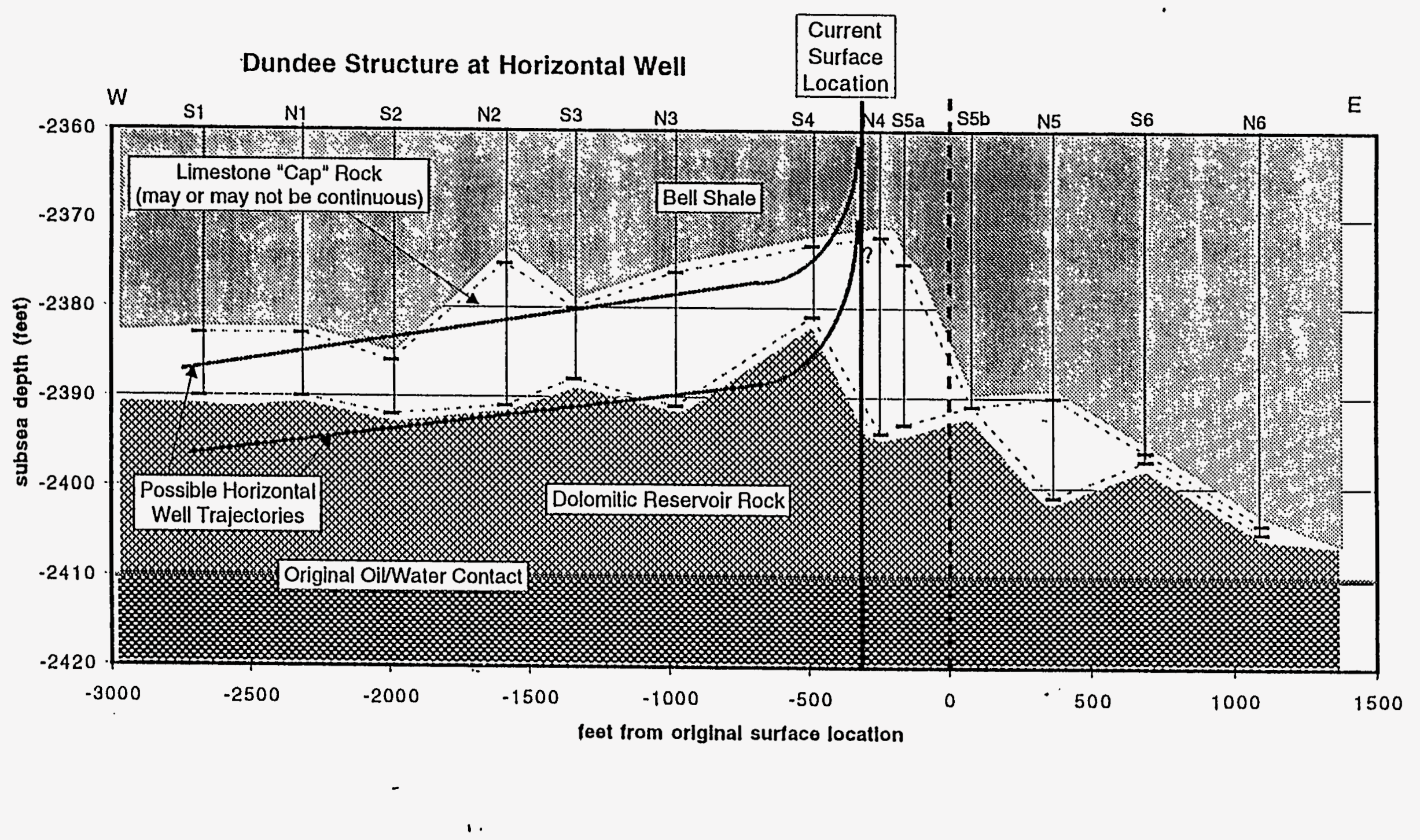

Figure 11 Schematic cross-section of horizontal well location in the Crystal Field. 
Figure 12 . 3-D volume visualization of the Michigan Basin prepared in MatLab. The lower surface is the top Silurian. The Dundee Formation, Bell Shale, and Antrim Shale are shown above the Silurian surface. North is to the right along the $\mathrm{X}$-axis.

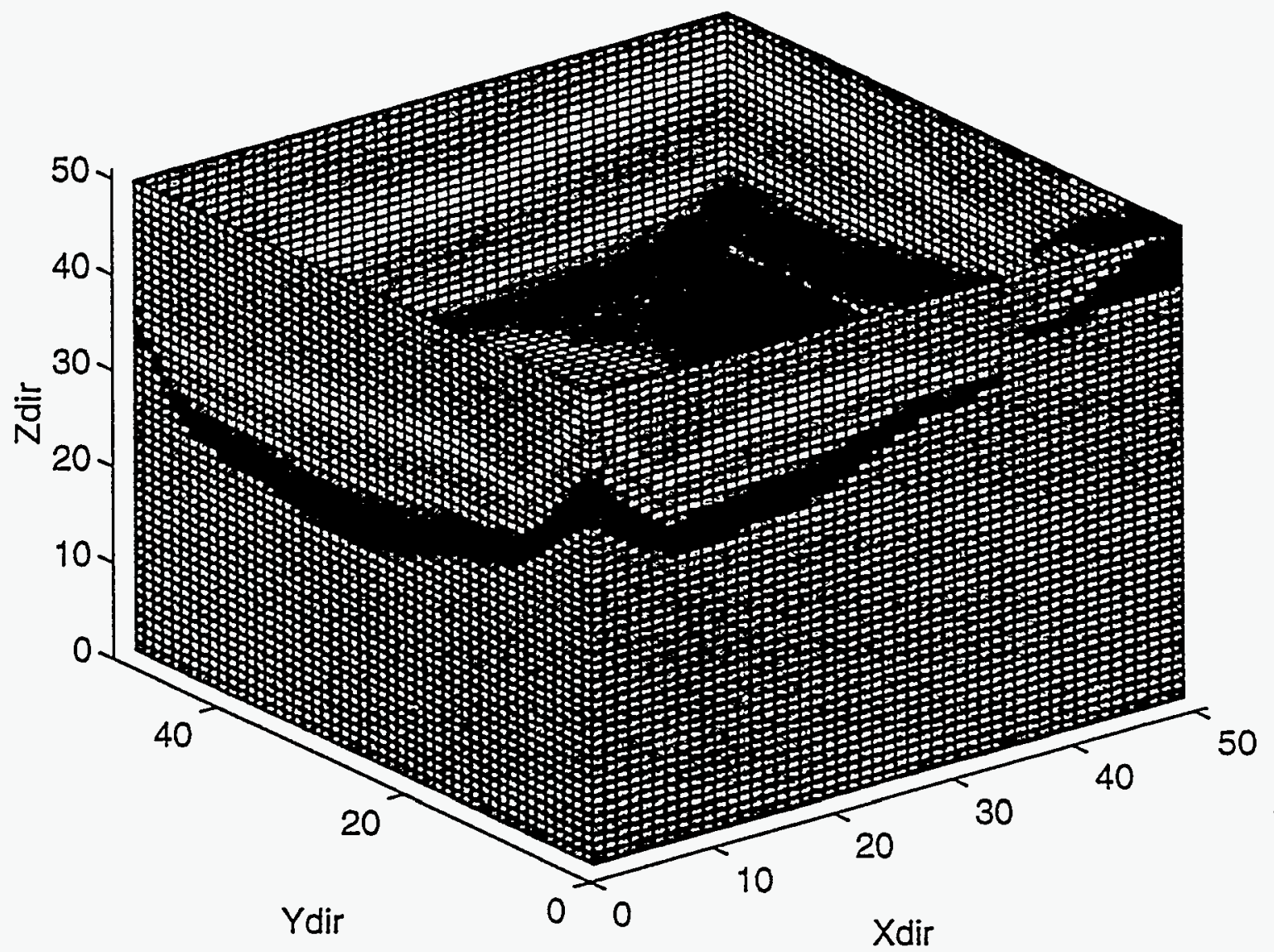




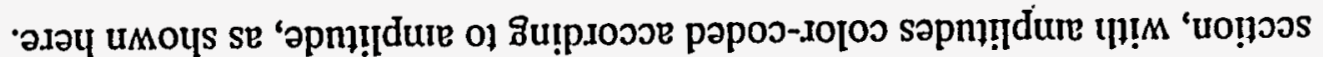

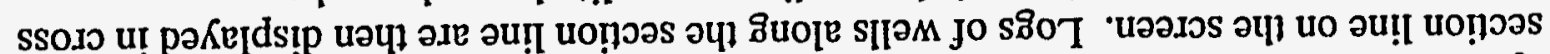

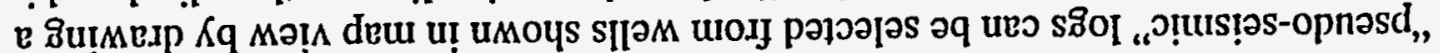

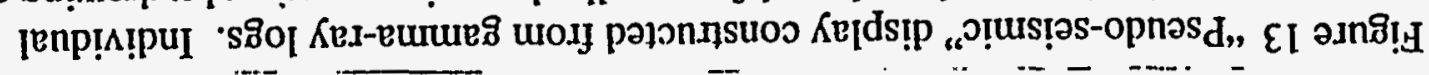
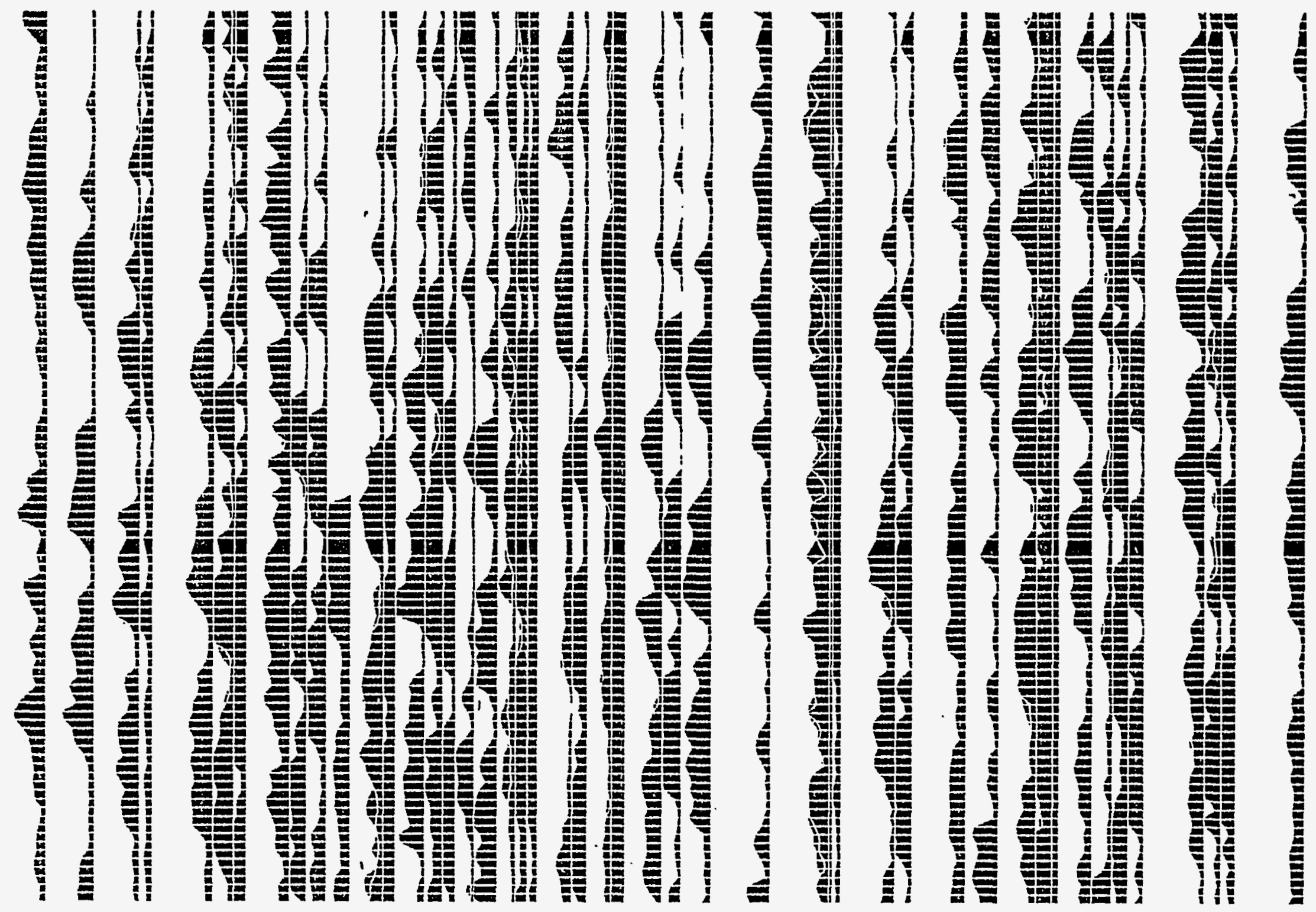
Attachment 1. Table of Contents, Practical Reservoir Characterization, by J. Huntoon and A. Wylie and J. Huntoon, to be published as a volume in the AAPG Computer Applications in Geology Series in early 1997. The reservoir characterization phase of this DOE Class 2 project was the impetus for this volume. 


\section{PRACTICAL RESERVOIR CHARACTERIZATION \\ Techniques for database construction and analysis io find and produce more oil and gas.}

A Nonjournal publication proposal to AAPG

\section{Purpose}

To provide a present-day cutting-edge guidebook to help the practicing explorationist, technical manager, and independent oil \& gas company understand the steps requirted in building a working, productive, bottom-line oriented, technical computer database. The use of this book will enable these individuals to significantly increase the value of their company's asset bases through the practical application of computer-based technical data mangement. Finally, it will aid them in recognizing the person-power, time, money, and management commitments needed to ensure a successful and productive reservoir characterization project.

A.S. 'Buddy' Wylie, Jr. and Jackie E. Huntoon

October 10, 1994 


\section{TABLE OF CONTENTS}

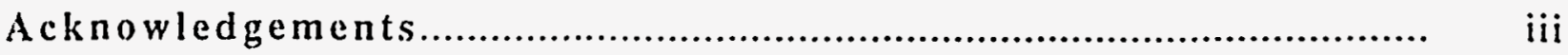

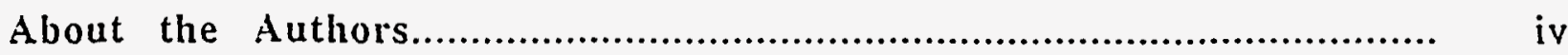

Abbreviations Used in the Text............................................................ v

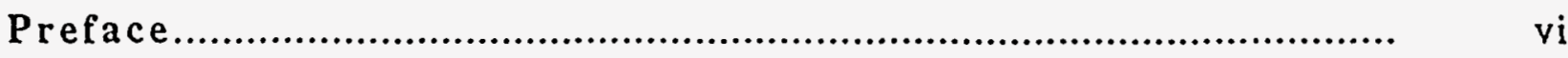

Chapter 1

Project Start-up (It is doable!).............................................................................

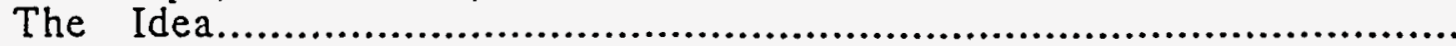

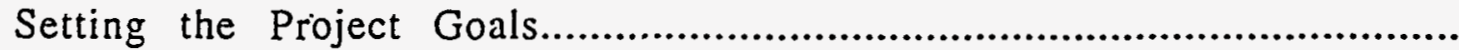

Planning - Timelines, Deadlines, and Gantt Charts.............................................

Staff and People Requirements...............................................................

Selection of Software, Hardware, and Digitizing Contractors

Quality Control and Accuracy Considerations.

Literature Review and Data Origins.

Chapter 2

How to Integrate the Accumulated Knowledge (Getting your arms around

the massive amount of data.).....

What are all these data elements anyway?

Basic data.

Basin/Field/Rock type specific.

Data Formats.

\section{Chapter 3}

The Data (You must know each data type's idiosyncrasies as well as its utilities.).

Field/Basin Information

Basic Well Data.

Lithologic Data.

Core Data

Log Data

Digitizing.

Uniform Log Curve Formats

Digitizing.

Drill Stem Test Data.

Production/Well Test/Injection Data

Laboratory Studies.

Still More Data - peculiarities to your field.

Reference Materials - remember those old chart books! 


\section{Chapter 4}

Prepping the Data for Interpretation (The nitty-gritty task of

quality controlling the data.)

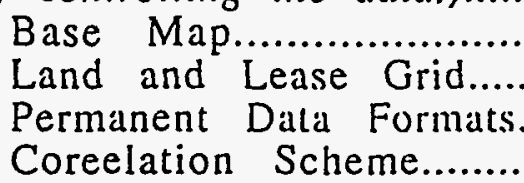

Seismic Analysis.....

Core Data.

Lithology Data....

Drill Stem Tests

Production and Well Tests

Log Curve Standardization

Log Normalization.

Rugosity Corrections

Log Transformation

Overburden Corrections

Planning for Future Updates

\section{Chapter 5}

Data Integration and Interpretation (You made it! Anything is possible now...).

Original Water Saturations.

Cross Sections.

Mapping.....

Initial and Testing

Structure Maps (Fluid Contacts)

Isopach/Isochore Maps.

Porosity, Permeability, and Saturation Maps

Environmental, Facies, and Lithology Maps.

Production Maps

Hydrodynamic Maps.

Seismic Maps.

Secondary and Enhanced Recovery Maps

"Sweet Spots" and Opportunity Maps.

Original Oil-in-Place and Volumetrics..

Workover Evaluation (Deepenings, Plugbacks, Liner Pulls, etc.)

New Drilling Evaluation.

Secondary/Tertiary Recovery Evaluation.... 


\section{Chapter 6}

Muti-well Analysis Téchniques (New peaks in creativity and productivity!).

Interconnecting the Geologic, Geophysical and Engineering Databases

Interactive Iterative Analysis.

Putting It All Together For That Management Presentation.

The Importance of Your Support Staffs and Co-workers

Chapter 7

Case Studies in Reservoir Characterization.

Bibliography \& References.

Index. 